OPEN ACCESS

Edited by:

Maria J. Buzon,

Vall d'Hebron Research Institute (NHIR), Spain

Reviewed by:

Alberto Bosque,

The George Washington University,

United States

Marta Massanella,

University of Montreal Hospital Centre

(CRCHUM), Canada

Maria Abad,

The University of North Carolina at

Chapel Hill, United States

*Correspondence:

Carine Van Lint

cvlint@ulb.ac.be

†These authors have contributed equally to this work

Specialty section:

This article was submitted to

Virology,

a section of the journal

Frontiers in Microbiology

Received: 18 October 2019

Accepted: 18 December 2019

Published: 24 January 2020

Citation:

Ait-Ammar A, Kula A, Darcis G,

Verdikt R, De Wit S, Gautier V, Mallon PWG, Marcello A, Rohr O and

Van Lint C (2020) Current Status of Latency Reversing Agents Facing the Heterogeneity of HIV-1 Cellular and Tissue Reservoirs.

Front. Microbiol. 10:3060. doi: 10.3389/fmicb.2019.03060

\section{Current Status of Latency Reversing Agents Facing the Heterogeneity of HIV-1 Cellular and Tissue Reservoirs}

\author{
Amina Ait-Ammar't, Anna Kula ${ }^{2+}$, Gilles Darcis ${ }^{3}$, Roxane Verdikt ${ }^{1}$, Stephane De Wit ${ }^{4}$, \\ Virginie Gautier ${ }^{5}$, Patrick W. G. Mallon ${ }^{5}$, Alessandro Marcello ${ }^{6}$, Olivier Rohr ${ }^{7}$ and \\ Carine Van Lint ${ }^{1 *}$
}

\begin{abstract}
'Service of Molecular Virology, Department of Molecular Virology (DBM), Université Libre de Bruxelles (ULB), Gosselies, Belgium, ${ }^{2}$ Malopolska Centre of Biotechnology, Laboratory of Virology, Jagiellonian University, Krakow, Poland, ${ }^{3}$ Infectious Diseases Department, Liège University Hospital, Liège, Belgium, ${ }^{4}$ Service des Maladies Infectieuses, CHU Saint-Pierre, Université Libre de Bruxelles, Bruxelles, Belgium, ${ }^{5}$ UCD Centre for Experimental Pathogen Host Research (CEPHR), School of Medicine, University College Dublin, Dublin, Ireland, ${ }^{6}$ Laboratory of Molecular Virology, International Centre for Genetic Engineering and Biotechnology (ICGEB), Trieste, Italy, ${ }^{7}$ Université de Strasbourg, EA7292, FMTS, IUT Louis Pasteur, Schiltigheim, France
\end{abstract}

One of the most explored therapeutic approaches aimed at eradicating HIV-1 reservoirs is the "shock and kill" strategy which is based on HIV-1 reactivation in latently-infected cells ("shock" phase) while maintaining antiretroviral therapy (ART) in order to prevent spreading of the infection by the neosynthesized virus. This kind of strategy allows for the "kill" phase, during which latently-infected cells die from viral cytopathic effects or from host cytolytic effector mechanisms following viral reactivation. Several latency reversing agents (LRAs) with distinct mechanistic classes have been characterized to reactivate HIV-1 viral gene expression. Some LRAs have been tested in terms of their potential to purge latent HIV-1 in vivo in clinical trials, showing that reversing HIV-1 latency is possible. However, LRAs alone have failed to reduce the size of the viral reservoirs. Together with the inability of the immune system to clear the LRA-activated reservoirs and the lack of specificity of these LRAs, the heterogeneity of the reservoirs largely contributes to the limited success of clinical trials using LRAs. Indeed, HIV-1 latency is established in numerous cell types that are characterized by distinct phenotypes and metabolic properties, and these are influenced by patient history. Hence, the silencing mechanisms of HIV-1 gene expression in these cellular and tissue reservoirs need to be better understood to rationally improve this cure strategy and hopefully reach clinical success.

Keywords: HIV-1, latency reversing agents, cure, latency, reservoirs, heterogeneity

\section{INTRODUCTION}

Approximately, 36.9 million people in the world are living with HIV, while there were 33.3 million in 2010, showing that HIV is still a global public health problem (UNAIDS 2018).

The development of ART has allowed the suppression of virus replication to undetectable levels. Thus, ART reduces HIV-associated morbidity, prolongs survival, prevents transmission, and results 
in a partial reconstitution of the immune system, as measured by an increase in circulating $\mathrm{CD}^{+}{ }^{+} \mathrm{T}$ cells. However, ART can cause cumulative toxic effects with the emergence of HIV-1 drugresistant variants ( $\mathrm{Hu}$ and Kuritzkes, 2014). Moreover, ART is unable to achieve complete virus eradication since it targets only actively replicating virus, and as such, treatment needs to be taken life-long. The main barrier to an HIV cure is the formation of stable reservoirs of latent HIV-1 that are defined as a cell type or an anatomical site in which integrated proviruses persist (Eisele and Siliciano, 2012). The latent reservoirs are highly heterogeneous and composed of multiple cell types, such as macrophages, but the best-characterized ones are a small population of HIV-1-infected memory $\mathrm{CD} 4^{+} \mathrm{T}$ cells. In addition to cellular reservoirs, GALT, CNS, genital tract, and lymph nodes are the main anatomical reservoirs of HIV-1 (Coombs et al., 2003; Gras and Kaul, 2010; Yukl et al., 2013). The role of the respiratory tract (Cribbs et al., 2015), liver (Penton and Blackard, 2014), kidney (Winston et al., 2001), and adipose tissue (Couturier et al., 2015) as HIV-1 reservoirs is also gaining importance. Moreover, an anatomical site in which ART penetration is limited (called a sanctuary) or a site which is immune-privileged (such as $B$ cell follicular centers within lymph nodes, testis, and the brain) may allow for residual replication contributing to viral persistence (Connick et al., 2007; Chomont et al., 2009; Buzón et al., 2011; Eisele and Siliciano, 2012; Fletcher et al., 2014). Together, these reservoirs can be induced to actively produce viruses by various cellular stimuli and therefore represent one potential source of rebound of viremia after ART interruption (Chun et al., 1997; Davey et al., 1999; Beliakova-Bethell et al., 2017; Ganor et al., 2019).

Abbreviations: 5-AzaC, 5-azacytidine; 5-azadC, 5-aza-2'deoxycytidine; 5'LTR, 5' Long Terminal Repeat; 7SK snRNP, 7SK small nuclear ribonucleoprotein; APOBEC3A, Apolipoprotein B mRNA editing enzyme, catalytic polypeptide-like 3 A; ART, Antiretroviral therapy; ASP, Antisense protein; BETis, Bromodomain and Extraterminal (BET) bromodomain inhibitors; B-HIVE, Barcoded HIV ensembles; CA-US, Cell associated unspliced; CCR5/6/7, CC chemokine receptor 6/7; CGi, CpG island; CSF, Cerebrospinal fluid; CTIP2, COUP-TF (Chicken Ovalbumin Upstream Promoter Transcription Factor)-Interacting Protein 2; CXCR3/5, C-XC Chemokine Receptor3/5; CNS, central nervous system; DCs, dendritic cells; DNA, Deoxyribonucleic acid; DNMT, DNA methyl-transferase; DSIF, DRB (5,6-dichloro-1-beta-D-ribofuranosylbenzimidazole) Sensitivity Inducing Factor; EDITS, Envelope Detection by Induced Transcription-based Sequencing; ESE $\mathrm{E}_{\text {tat }}$, Exonic Splice Enhancer tat; ESR-1, Estrogen receptor-1; EZH2, Enhancer Of Zeste 2 Polycomb Repressive Complex 2 Subunit; fDCs, follicular dendritic cells; GALT, Gut-Associated Lymphoid Tissue; HDAC, histone deacetylase; HIV, human immunodeficiency virus; HLA-DR, Human Leukocyte Antigen - DR isotype; HMBA, Hexamethylene bisacetamide; HP1, heterochromatin Protein 1; HSCs, hematopoietic Stem Cells; IL-2/4/7/15, Interleukin 2/4/7/15; ITIM, Immunoreceptor Tyrosine-based Inhibitory Motif; KAP1, KRAB (KrüppelAssociated Box) domain-Associated Protein 1; LAG-3, Lymphocyte Activation Gene-3; LARA, latency and reversion assay; lncRNA, Long non-coding RNA; LRA, latency-reversing agents; MAPK, mitogen-activated protein kinase; MATR3, Matrin 3; mDCs, myeloid dendritic cells; miRNA, Micro ribonucleic acid; MMQO, 8-methoxy-6-methylquinolin-4-ol; Nef, negative regulatory factor; NELF, Negative Elongation Factor; NFAT, Nuclear Factor of Activated T-cells; NF-кB, Nuclear Factor-kB; PBMCs, peripheral blood mononuclear cells; PCAF, p300/CBP (CREB Binding Protein)-Associated Factor; PD-1, programmed cell death-1; PHA, phytohemagglutinin; PMA, phorbol myristate acetate; PML, promyelocytic leukemia protein; PRC2, polycomb repressive complex 2; PSF, polypyrimidine tract-binding protein associated splicing factor; PTB, Polypyrimidine Tract Binding protein; P-TEFb, Positive Transcription Elongation Factor b; qPCR, Quantitative polymerase chain reaction; QVOA, quantitative viral outgrowth
Viruses have developed different mechanisms to escape the host immune system. In addition to the rapid evolution of viral variants, the establishment of viral latency in the infected cells is one of these mechanisms (Deng et al., 2015). Latently-infected cells contain stably-integrated, replication-competent proviruses repressed by a plethora of silencing mechanisms operating at the transcriptional and post-transcriptional levels. The number of latently-infected cells carrying replication-competent proviruses is extremely low with a majority of defective proviruses (Ho et al., 2013; Bruner et al., 2016, 2019). Significant progress has been made in the development of various therapeutic approaches that target HIV-1 and prevent disease progression. Currently, two strategies are under investigation in order to reach longterm control of viral replication in the absence of ART: the first strategy is aiming at achieving a sterilizing cure (i.e., a total elimination of the virus from the human body), whereas the second is a functional cure (i.e., a remission or long-term control of HIV-1 in the absence of ART, without loss of CD4 ${ }^{+}$ $\mathrm{T}$ cells, no clinical progression, lack of HIV-1 transmission, and a reduction of the size of the reservoirs). Given the difficulty of achieving a sterilizing cure, one specific approach for a functional cure, called the "shock and kill" strategy, has become one of the major focus of attention (Thorlund et al., 2017). However, it now appears that the main barrier to reaching success with this "shock and kill" strategy is the heterogeneity of the latent HIV-1 reservoirs that is reflected by the diversity of infected cell types residing in the blood and in the different tissues and by the complexity of the molecular mechanisms governing latency and most likely differing from one cell to the other.

The present review will discuss the heterogeneity of the HIV-1 reservoirs that has been highlighted by studies using LRAs. We will describe the determinants responsible for these heterogeneous responses to LRAs, including the diversity of cell types composing the reservoirs (their origin, their differentiation, and their activation state). We will briefly present the multiple molecular mechanisms governing latency, the HIV-1 diversity within the latent and reactivated reservoirs, the patient-to-patient and cellular variations in response to LRAs. Finally, we will discuss why a better understanding of these elements is crucial for reaching an HIV-cure.

assays; Rev, regulator of virion expression; RNA, ribonucleic acid; RNAPII, RNA polymerase II; RT-ddPCR, teverse transcription droplet digital PCR; SAHA, suberoylanilide hydroxamic acid; SIV, simian immunodeficiency virus; SMAC, second mitochondrial activator of caspases; SMYD2, SET (Suppressor of variegation, Enhancer of Zeste, Trithorax) and MYND (Myeloid-NervyDEAF1) domain-containing protein 2; Sp1, specificity protein 1; STAT5, signal transducer and activator of transcription 5; Suv39H1, Suppressor of variegation 3-9 homolog 1; TAR, transactivation response element; Tat, transactivator of transcription; $\mathrm{T}_{\mathrm{CM}}$, central memory $\mathrm{CD}^{+} \mathrm{T}$ cells; TCR, $\mathrm{T}$ Cell Receptor; $\mathrm{T}_{\mathrm{EM}}$, effector memory $\mathrm{CD}^{+} \mathrm{T}$ cells; $\mathrm{T}_{\mathrm{fh}}, \mathrm{T}$ follicular helper cells; Th17, $\mathrm{T}$ helper cells 17; TIGIT, T-cell immunoreceptor with Ig ITIM domains; Tim-3, $\mathrm{T}$ cell immunoglobulin and mucin 3; TILDA, Tat/rev-induced limiting dilution assay; $\mathrm{T}_{\mathrm{N}}$, Naïve $\mathrm{CD}^{+} \mathrm{T}$ cells; $\mathrm{TNF} \alpha$, tumor necrosis factor alpha; $\mathrm{T}_{\text {reg }}$, Regulatory CD4 ${ }^{+}$T cells; TRIM19, Tripartite Motif 19/22; TSA, trichostatin A; TSCM, stem cell-like memory $\mathrm{CD}^{+}{ }^{+} \mathrm{T}$ cells; TSS, transcription start site; $\mathrm{T}_{\mathrm{TD}}$, terminally differentiated $\mathrm{CD} 4^{+} \mathrm{T}$ cells; $\mathrm{T}_{\mathrm{TM}}$, Transitional memory CD $4^{+}$ $\mathrm{T}$ cells; UNAIDS, United Nations Programme on HIV and AIDS; UPF-1, up-frameshift protein 1 . 


\section{HETEROGENEOUS COMPOSITION OF HIV-1 RESERVOIRS}

\section{CD4 $^{+} \mathbf{T}$ Cell Reservoirs}

HIV-1 infects subsets of CD4 ${ }^{+} \mathrm{T}$ lymphocytes, leading either to productively-infected cells or, rarely, to latently-infected cells. HIV-1 infected CD4 ${ }^{+}$T cells can be distinguished either by their state of differentiation, by their function, or by the markers they express on their surface.

\section{CD4 ${ }^{+} \mathrm{T}$ Cell Differentiation Subsets}

$\mathrm{CD} 4^{+} \mathrm{T}$ cells infected with HIV-1 can be grouped by their state of differentiation into naive $\mathrm{T}$ cells $\left(\mathrm{T}_{\mathrm{N}}, \mathrm{CD}_{45 \mathrm{RA}}{ }^{+}, \mathrm{CD} 2 \mathrm{~L}^{+}\right.$, and $\mathrm{CD}^{-} 5^{-}$) and memory $\mathrm{CD} 4^{+} \mathrm{T}$ cells, which can be further divided into four subpopulations: central memory $\mathrm{T}$ cells $\left(\mathrm{T}_{\mathrm{CM}}\right.$, $\mathrm{CD} 4 \mathrm{RA}^{-}, \mathrm{CCR}^{+}$, and $\mathrm{CD}^{+} 7^{+}$), effector memory $\mathrm{T}$ cells $\left(\mathrm{T}_{\mathrm{EM}}, \mathrm{CD} 4 \mathrm{RA}^{-}, \mathrm{CCR}^{-}\right.$, and $\left.\mathrm{CD}^{-} 7^{-}\right)$, transitional memory T cells $\left(\mathrm{T}_{\mathrm{TM}}, \mathrm{CD} 4 \mathrm{RA}^{-}, \mathrm{CCR}^{-}\right.$, and $\left.\mathrm{CD} 27^{+}\right)$, and stem celllike memory $\mathrm{T}$ cells $\left(\mathrm{T}_{\mathrm{SCM}}, \mathrm{CD} 45 \mathrm{RA}^{+}, \mathrm{CCR}^{+}, \mathrm{CD} 27^{+}\right.$, and $\left.\mathrm{CD}^{+} 5^{+}\right) . \mathrm{T}_{\mathrm{N}}$ cells that are more resistant to HIV-1 infection than memory $\mathrm{CD}^{+}{ }^{+} \mathrm{T}$ cells and as such contain lower levels of HIV1 DNA (Venanzi Rullo et al., 2019), produce as many virions (Zerbato et al., 2019) or greater (Venanzi Rullo et al., 2019) amount of replication-competent $\mathrm{HIV}-1$ than the memory $\mathrm{CD} 4{ }^{+}$ $T$ cells following latency reversal with LRAs, indicating that $T_{N}$ cells are an important reservoir of latent HIV-1. Moreover, the total proportion of $\mathrm{T}_{\mathrm{N}}$ increases under ART regimen compared to memory $\mathrm{T}$ cells (Wightman et al., 2010). However, clonal expansion is more frequently observed in memory than in $T_{N}$ cells, thus contributing to HIV-1 persistence (von Stockenstrom et al., 2015). Indeed, homeostatic proliferation driving clonal expansion has been evidenced by pioneering work of Chomont et al. (2009) that identified $\mathrm{T}_{\mathrm{CM}}$ and $\mathrm{T}_{\mathrm{TM}}$ as the main reservoir for HIV-1 infection. These two major subgroups are a more stable reservoir for $\mathrm{HIV}-1$ than $\mathrm{T}_{\mathrm{EM}}$ which are short-lived and, unlike $\mathrm{T}_{\mathrm{CM}}$ and $\mathrm{T}_{\mathrm{TM}}$, express markers of activation (HLADR) (Pardons et al., 2019) and might be more sensitive to programmed cell death (Riou et al., 2007; Chomont et al., 2009; Cockerham et al., 2014). It has been previously shown by the group of Sarah Palmer that $\mathrm{T}_{\mathrm{EM}}$ which are in an activation state carry the highest number of intact proviruses compared to $\mathrm{T}_{\mathrm{CM}}, \mathrm{T}_{\mathrm{TM}}$, and $\mathrm{T}_{\mathrm{N}}$ (Hiener et al., 2017). This finding suggests that the resting phenotype of $\mathrm{CD}^{+} \mathrm{T}$ cells (i.e., characterized by no expression of activation markers) is not a prerequisite for latent infection. These differences could be explained by patient-specific variations related to the duration of infection before ART initiation or to the duration of ART. Moreover, some evidence supports the theory that HIV-1 can establish latent infection in actively replicating $\mathrm{CD} 4^{+} \mathrm{T}$ cells, suggesting that HIV-1 infection of both resting and activated primary $\mathrm{CD}^{+}$ $\mathrm{T}$ cells could result in latency (Chavez et al., 2015). The $\mathrm{T}_{\mathrm{TD}}$, corresponding to aged T-cell populations that reflect $\mathrm{HIV}-1$ disease progression (Cao et al., 2009) and in which integrated HIV-1 DNA is also detected, are a very small reservoir with a reduced frequency in HIV-1 individuals under suppressive ART and improved CD4 ${ }^{+}$T cell counts (Chomont et al., 2009; Behrens et al., 2018). Finally, $\mathrm{T}_{\mathrm{SCM}}$ are permissive to HIV-1 infection and contribute to its persistence by their capacity of self-renewal and prolonged survival rate. The proportion of viral DNA associated with these $\mathrm{T}_{\mathrm{SCM}}$ cells is higher than in $\mathrm{T}_{\mathrm{CM}}$. Although $\mathrm{T}_{\mathrm{SCM}}$ are latently-infected, they represent only a small fraction of the total reservoir (Gattinoni et al., 2011; Buzon et al., 2014).

\section{CD4 ${ }^{+}$T Cell Functional Subsets}

Different $\mathrm{CD}^{+}{ }^{+} \mathrm{T}$ cell subsets that are generated from $\mathrm{T}_{\mathrm{N}}$ were shown to be HIV-1 infected. For instance, resting CD ${ }^{+} \mathrm{CD} 25^{+}$ $\mathrm{T}_{\text {reg }}$ were found to be sensitive to HIV-1 infection acting as a viral reservoir in patients under long ART (Tran et al., 2008). These cells are characterized by a lesser response to $\mathrm{T}$ cell activation which limits virus expression and inhibits $\mathrm{CD} 8^{+} \mathrm{T}$-cell cytotoxic function (Tran et al., 2008; Pardons et al., 2019). Additionally, the gamma-delta $\mathrm{T}$ cells $(\gamma \delta \mathrm{T})$ which represent approximately 2 to $10 \%$ of total circulating $\mathrm{CD}^{+} \mathrm{T}$ lymphocytes and whose majority express TCR from V $\delta 2$ variable regions (hereafter referred as $\mathrm{V} \delta 2$ cells), are classified as memory cells according to the expression of CD45RO and CD27 markers (Miyawaki et al., 1990). These V $\delta 2$ cells have been documented to be productively infected and depleted upon HIV-1 infection (Li and Pauza, 2011). More recently, it has been demonstrated that V $\delta 2$ cells in ARTtreated patients with complete suppression of HIV-1 plasma viremia harbor latent $\mathrm{HIV}-1$ that can replicate following ex vivo stimulation indicating that peripheral V $\delta 2 \mathrm{~T}$ cells are a potential HIV-1 reservoir (Soriano-Sarabia et al., 2015). Also, Th17 CCR6 ${ }^{+}$ memory $\mathrm{CD}^{+}{ }^{+} \mathrm{T}$-cell subsets in the blood and colon are longlived cells that act as HIV-1 reservoirs during ART (Gosselin et al., 2010, 2017; Pardons et al., 2019). In addition, T follicular helper cells $\left(\mathrm{T}_{\mathrm{fh}}\right)$ from the germinal center and peripheral blood $\left(\mathrm{pT}_{\mathrm{fh}}\right)$ are highly susceptible to HIV-1 infection holding replicationcompetent virus and serve as reservoirs during ART (Perreau et al., 2013; Pallikkuth et al., 2015; Kohler et al., 2016; Pardons et al., 2019). These cells are characterized by surface expression of CXCR5 and PD-1, reside in the lymph node follicles in immediate anatomical proximity to B cells, and support the germinal center reaction essential for the generation of effective humoral immunity. Notably, the group of Matthieu Perreau, by investigating lymph node $\mathrm{T}_{\mathrm{fh}}$ (expressing CXCR5 and PD-1) and $\mathrm{pT}_{\mathrm{fh}}$ (expressing CXCR3), has shown that these subpopulations are the major sources of infectious replication-competent HIV-1 (Banga et al., 2016b, 2018).

Very recently, resident memory $\mathrm{CD} 4^{+} \mathrm{T}$ cells $\left(\mathrm{T}_{\mathrm{RM}}\right)$, present in tissues such as the lower female genital tract has been described as a critical HIV-1 reservoir in cervical mucosa (Cantero-Pérez et al., 2019). Interestingly, cervical tissues from aviremic ARTtreated HIV-1 infected woman contained higher viral DNA content compared to blood samples and showed that $\mathrm{CD} 4^{+} \mathrm{T}_{\mathrm{RM}}$ harboring viral DNA and viral RNA are the main contributors to this reservoir.

\section{Markers of Latently-Infected CD4 ${ }^{+}$T Cells}

Studies investigating the role in latency of activation markers such as HLA-DR and immune checkpoint molecules (i.e., PD-1, LAG-3, TIGIT and Tim-3) have indicated that these markers are preferentially expressed at the surface of memory 
$\mathrm{CD}^{+} \mathrm{T}$ cells $\left(\mathrm{T}_{\mathrm{CM}}\right.$ and $\mathrm{T}_{\mathrm{TM}}$ ) harboring latent HIV-1 provirus (Fromentin et al., 2016; Evans et al., 2018; Pardons et al., 2019). Although several studies, including those carried on SIVinfected macaques, have demonstrated that cells expressing these markers carry latent, replication-competent integrated viral DNA (Chomont et al., 2009; Hurst et al., 2015; Banga et al., 2016b; Fromentin et al., 2016; McGary et al., 2017), the replication competence of the integrated proviruses and the contribution of the cells bearing these markers to the latent reservoir still need to be fully elucidated.

Recently, the expression of CD32a has been reported as a potential marker of memory $\mathrm{CD}^{+} \mathrm{T}$ cells harboring a replication-competent latent virus in aviremic patients under ART (Descours et al., 2017; Darcis et al., 2019). The role of CD32a as a cellular marker of HIV-1 reservoirs has been the subject of several works (Abdel-Mohsen et al., 2018; Martin et al., 2018; Osuna et al., 2018; Thornhill et al., 2019). A complete study presented at CROI by Darcis et al. (CROI 2019, Poster $346-\mathrm{CD} 32^{+} \mathrm{CD} 4{ }^{+} \mathrm{T}$ cells are enriched in HIV-1 DNA) showed that active $\mathrm{CD} 4^{+} \mathrm{T}$ cells co-expressing HLA-DR and CD32a are highly enriched with HIV-1 DNA.

The integrin $\alpha 4 \beta 7$ has been shown on a $\mathrm{T}$ cell subset that is highly susceptible to HIV-1 infection (Cicala et al., 2009; Sivro et al., 2018). Moreover, the integrin $\alpha 4 \beta 1$ was shown to be expressed by more than $70 \%$ of infected cells both in untreated and ART-suppressed individuals (Pardons et al., 2019). Integrins mediate the adhesion and transendothelial migration of lymphocytes facilitating their homing to GALT (for $\alpha 4 \beta 7$ ) and to the inflamed central nervous system/bone marrow (for $\alpha 4 \beta 1$ ) suggesting a role in HIV-1 persistence by enhancing $\mathrm{T}$ cell expansion.

In addition, high levels of CD2 receptor expression on latently infected resting memory $\mathrm{CD}^{+} \mathrm{T}$ cells in virally suppressed HIV-1-infected subjects has been also identified (Iglesias-Ussel et al., 2013). Moreover, CD30 receptor was identified on transcriptionally active $\mathrm{CD}^{+}{ }^{+}$lymphocytes in individuals on suppressive ART suggesting that it might be a marker of residual, transcriptionally active HIV-1 infected cells in the setting of suppressive ART (Hogan et al., 2018). Last but not least, very recently the $\mathrm{B}$ lymphocyte antigen CD20 has also been identified as a marker of transcriptionally-active HIV-infected cells (Serra-Peinado et al., 2019).

\section{Non-T Cell Reservoirs}

Even though memory $\mathrm{CD}^{+}{ }^{+} \mathrm{T}$ cells are a long-term cellular reservoir for HIV-1, they are not the only source of viral rebound during treatment interruption. Macrophages, DCs, and tissue macrophages, such as microglial cells, are part of the viral reservoir (Kumar et al., 2014; Kandathil et al., 2016; Honeycutt et al., 2017; Schwartz et al., 2019).

Indeed, overwhelming evidence supports the notion that tissues, such as the CNS (Canestri et al., 2010; Gras and Kaul, 2010), lymph nodes (Sewald et al., 2015), testes (Darcis et al., 2016; Jenabian et al., 2016), gut (Yukl et al., 2013), genital tract (Iversen et al., 2004; Marcelin et al., 2008; Sheth et al., 2009), and lungs (Costiniuk and Jenabian, 2014), serve as HIV-1 sanctuaries that counteract viral eradication. In this regard, the group of Morgane Bomsel has recently reported that urethral tissue macrophages expressing IL-1 receptor, CD206, and IL-4 receptor, but not CD163, constitute a replicationcompetent HIV-1 reservoir (Ganor et al., 2019). Importantly, lipopolysaccharides specifically reactivate the production of replication-competent infectious proviruses from these tissue macrophages (Ganor et al., 2019).

In the case of circulating monocytes, they are more resistant to HIV-1 infection and their contribution as a viral reservoir is controversial and remains debatable. Monocytes have been proposed as a vehicle of HIV-1 dissemination throughout the body upon their entry in tissues where they differentiate into macrophages. Especially, due to their ability to cross the bloodtissue barrier, monocytes consequently, spread the infection into sanctuaries such as the brain (Pulliam et al., 1997; Valcour et al., 2009, 2010, 2013; Williams et al., 2014). These characteristics indicated the monocytes as an important viral reservoir. However, even if several studies have reported persistent infection of monocytes in ART treated individuals (Lambotte et al., 2000; Sonza et al., 2001; Gibellini et al., 2008), others failed to detect HIV-1 in circulating monocytes (Almodóvar et al., 2007). A recent work from the group of Nicolas Chomont indicated that monocyte infection is infrequent, and they highlighted the importance of using flow cytometry cell-sorting to minimize contamination by CD4 ${ }^{+}$T cells (Massanella et al., 2019).

Follicular dendritic cells (fDCs) in lymphoid tissues specialized in the trapping and retention of antigens in the form of immune complexes on their surface, including HIV-1 virions, can serve as a potential viral reservoir (Smith et al., 2001). Using specific and sensitive next-generation in situ hybridization approach, Deleage et al. (2016) documented the importance of B cell follicles in active, latent, and persistent infections by analyzing lymphoid tissues from macaques prior to and during ART. These fDCs could thus transfer the virus to $\mathrm{T}$ cells present in the follicles of secondary lymphoid organs (Heesters et al., 2015). In addition, myeloid dendritic cells (mDCs) located in the lymph nodes may support a very low level of viral replication and have a role in HIV-1 latency (Shen et al., 2014). However, the mechanism of viral persistence in these cells is not yet clearly understood [reviewed in Kandathil et al. (2016)].

Viral DNA has also been detected in hematopoietic stem cells (HSCs) from ART-treated patients, which could demonstrate their involvement in HIV-1 persistence (Sebastian et al., 2017; Zaikos et al., 2018). Despite the limited infection and detection of HSCs in a subset of patients (McNamara et al., 2013), their role as a viral reservoir may be crucial. Finally, HIV-1 can infect kidney allografts after transplantation despite undetectable viremia thereby suggesting that podocytes can serve as viral reservoirs and revealing once again the heterogeneous composition of the HIV-1 reservoir (Canaud et al., 2014).

In conclusion, multiple cell subsets being present at various cellular differentiation states, either resting or activated, can serve as HIV-1 reservoir. All these cells contribute to the complexity and heterogeneity of the reservoirs of latent HIV-1. It is very likely that different molecular mechanisms of latency establishment 
and persistence are involved in different latently-infected cell types and even may vary among cells of the same lineage.

\section{COMPLEXITY OF MOLECULAR MECHANISMS REGULATING HIV-1 LATENCY}

It is well established that repression of HIV-1 expression is mediated through a plethora of molecular mechanisms both for the establishment and for the maintenance of postintegration latency (summarized in Figure 1). In fact, HIV-1 latency is a multifactorial phenomenon, controlled by several interlinked mechanisms operating at the transcriptional and post-transcriptional levels [reviewed in Van Lint et al., 2013)] and influenced by the transcriptional program of the host cell (Bradley et al., 2018). For instance, some studies have suggested that HIV-1 viral latency is related to the integration site and orientation of the provirus (Greger et al., 1998; Han et al., 2008; Lenasi et al., 2008; Chen et al., 2017; Einkauf et al., 2019). HIV-1 integration seems random but favors the introns of transcriptionally-active genes located in gene dense regions in the outer shell of the nucleus close to the nuclear pores (Schröder et al., 2002; Han et al., 2004; Marini et al., 2015; Singh et al., 2015; Chen et al., 2017). The importance of transcriptional interference as a mechanism suppressing the expression of the integrated provirus (including steric hindrance, convergent transcription, and enhancer trapping) has also been proposed (Greger et al., 1998; Han et al., 2008; Lenasi et al., 2008) [reviewed in Colin and Van Lint (2009)].

Moreover, during latency, the HIV-1 promoter is heavily controlled by epigenetic mechanisms, including DNA methylation (Blazkova et al., 2009; Kauder et al., 2009; Chávez et al., 2011) and histone post-translational modifications, such as histone acetylation (Lusic et al., 2003; Jiang et al., 2007; Tyagi and Karn, 2007; Li et al., 2018), methylation (du Chéné et al., 2007; Marban et al., 2007; Imai et al., 2010; Friedman et al., 2011; Ding et al., 2013; Tchasovnikarova et al., 2015, 2017; Boehm et al., 2017; Nguyen et al., 2017; Zhang et al., 2017; Huang et al., 2019), and crotonylation (Jiang et al., 2018). The degree of DNA methylation on the HIV-1 promoter was long considered controversial due to conflicting observations in patients (Blazkova et al., 2009, 2012; Kauder et al., 2009; Ho et al., 2013; Weber et al., 2014). However, this heterogeneity in promoter methylation profile between patients has now been explained by the duration of the infection (Palacios et al., 2012) and/or the duration of ART therapy (Trejbalová et al., 2016) which impacts the accumulation of cytosine methylation on the 5'LTR. Still, the exact mechanisms of this DNA methylation accumulation in the latent reservoir of HIV-1-infected individuals remain unclear.

Additionally, an antisense transcript originating from the 3'LTR (named the ASP RNA) (Zapata et al., 2017) was recently shown to recruit the PRC2 repressor complex to the HIV-1 5'LTR, increasing the repressive epigenetic mark H3K27me3 while reducing RNAPII occupancy at the viral promoter and promoting the establishment and maintenance of HIV-1 latency at the epigenetic level (Zapata et al., 2017).
An HIV-encoded antisense long non-coding RNA directs the same epigenetic silencing mechanisms by recruiting and guiding chromatin-remodeling complex consisting of proteins such as DNMT3a, EZH2, and HDAC-1 to the viral promoter leading to transcriptional HIV-1 latency (Saayman et al., 2014).

HIV-1 latency is also associated with poor availability of transcriptional activating factors including NF- $\mathrm{KB}$, NFAT, and STAT5 due to their cytoplasmic sequestration (Williams et al., 2006; Della Chiara et al., 2011; Hakre et al., 2012; Bosque et al., 2017) and with a low expression level of the viral transactivator Tat (Burnett et al., 2009; Weinberger et al., 2005). The interaction of the cellular transcriptional cofactor CTIP2 with HP1 $\alpha$ is involved in the relocation of Tat to transcriptionally inactive regions of the chromatin (Rohr et al., 2003). However, HIV-1 counteracts CTIP2 mediated-repression by promoting its degradation by the HIV-1 accessory protein Vpr (Forouzanfar et al., 2019). Another recent finding has revealed that APOBEC $3 \mathrm{~A}$, the restriction factor that suppresses HIV-1 infection in macrophages, maintains HIV-1 latency by recruiting KAP1 and HP1 inducing repressive histone marks (Taura et al., 2019). In addition, the importance of TRIM22, known to inhibit the binding of Sp1 to the $5^{\prime}$ LTR promoter (Turrini et al., 2015) and to colocalize with HIV-1 transcriptional repressors TRIM19/PML (Forlani et al., 2017), contributes to the maintenance of HIV-1 latency (Turrini et al., 2019).

During latency and even after transcription initiation, the RNAPII is paused during early elongation, constraining its processivity and resulting in repression of HIV-1 gene expression (Adams et al., 1994). RNAPII terminates prematurely and accumulates at specific positions of the HIV-1 promoter that overlap with the position of the repressive nucleosome nuc-1, positioned in the $5^{\prime}$ LTR just after the TAR region, inducing a block of transcriptional elongation (Verdin et al., 1993). This inhibition of HIV-1 transcription elongation is regulated by the binding of negative factors such as NELF and DSIF to the RNAPII (Yamaguchi et al., 1999; Jadlowsky et al., 2014) and by the limited availability of the cellular transcription factor P-TEFb due to its sequestration by the 7SK snRNP complex (Nguyen et al., 2001; Yang et al., 2001; Cherrier et al., 2013; Eilebrecht et al., 2014). $\mathrm{P}-\mathrm{TEFb}$ is composed of CyclinT1 and CDK9 and requires the CDK9 Thr-186 phosphorylation for its activity to mediate the phosphorylation of the C-terminal domain of the paused RNAPII antagonizing its negatives factors (Wei et al., 1998; Ramakrishnan et al., 2009). The level of CDK9 phosphorylation has been found to be lower in resting $\mathrm{CD}^{+} \mathrm{T}$ cells harboring latent HIV-1 (Budhiraja et al., 2013; Ramakrishnan et al., 2015). Furthermore, CTIP2 binds to the 7SK snRNP complex to inhibit P-TEFb and HIV-1 transcription in microglial cells (Cherrier et al., 2013; Eilebrecht et al., 2014).

Abortive TAR transcripts have been reported even during transcriptional elongation block (Adams et al., 1994; Core and Lis, 2008; Kaiser et al., 2017). In a very elegant manner, the group of Steven Yukl has evidenced that multiple blocks to transcription and even to splicing and export exist in patient cells. They developed a panel of RT-ddPCR assays to measure at the same time different HIV-1 transcripts (Telwatte et al., 2018; Yukl et al., 2018) in patient-derived 


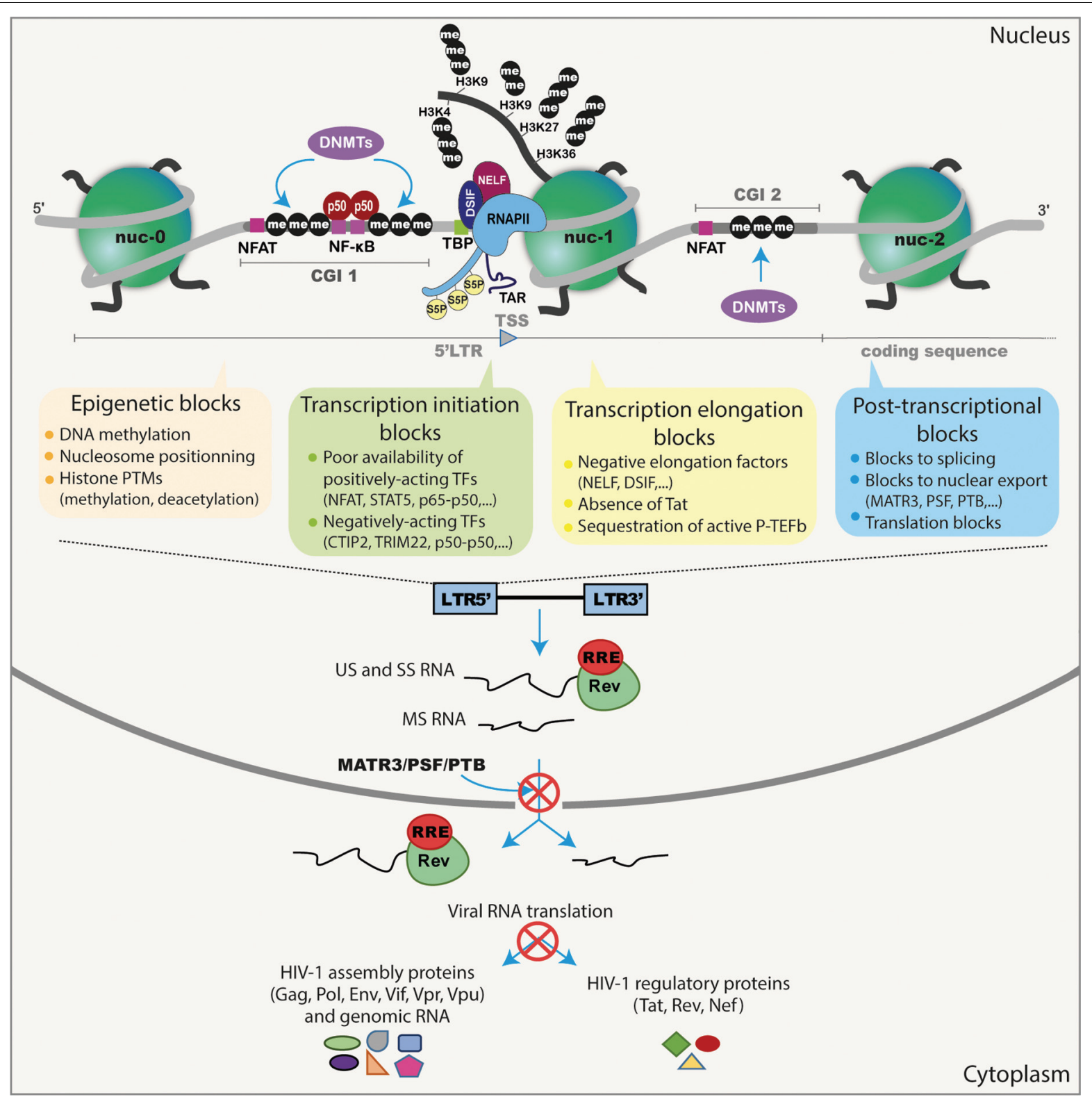

FIGURE 1 | Schematic representation of the different transcriptional and post-transcriptional blocks involved in HIV-1 latency. During HIV-1 latency, several blocks preventing viral production have been described. These are represented by the methylation of the two CGIs surrounding the HIV-1 TSS and the deposit of repressive epigenetic marks (histone deacetylation and methylation) maintaining the repressive nucleosome nuc-1 positioned in the HIV-1 5'LTR promoter just downstream the TSS. The transcription initiation is also blocked because of the cytoplasmic sequestration of the positive NF-kB heterodimer p50-p65 and the phosphorylated NFAT and STAT5. The presence of repressive factors (such as CTIP2, TRIM22 and the binding of the homodimer p50-p50 to the NF-kB binding sites in the HIV-1 promoter) acts negatively on HIV-1 transcription initiation. The RNAPII, with its phosphorylated serine 5 (S5P) residue in its C-terminal domain, pauses and accumulates at the promoter-proximal region due to the binding of the negative factors NELF and DSIF. The elongation is also blocked by the absence of the master regulator of viral transcription Tat and by the sequestration of the positive transcriptional elongation factor P-TEFb into the inactive complex named 7 SK snRNP. The splicing and export of HIV-1 transcripts are inefficient during latency due to the low expression level of post-transcriptional factors such as PTB, MATR3, and PSF. Finally, translation of viral transcripts could be inhibited by mechanisms involving mRNA degradation and sequestration in cytoplasmic granules.

cells. They quantified the transcripts suggestive of transcriptional interference (U3-U5), initiation (TAR), $5^{\prime}$ elongation (R-U5-preGag), distal transcription (Nef), completion (U3-polyA), and multiple splicing (Tat-Rev) (Yukl et al., 2018). Using blood $\mathrm{CD}^{+}{ }^{+} \mathrm{T}$ cells from HIV-1 individuals under ART, they showed a greater block to HIV-1 transcriptional elongation, distal
HIV-1 transcription, completion, and multiple splicing than to transcriptional initiation (Yukl et al., 2018). This transcription profiling approach highlighted the blocks at distinct stages of HIV-1 transcription and splicing (which may be governed by different mechanisms), thereby underlying the heterogeneity of HIV-1 latency in $\mathrm{CD} 4^{+} \mathrm{T}$ cells. 
The work of Telwatte et al. (2018) and Yukl et al. (2018) and also of Pace et al. (2012) have highlighted the importance of post-transcriptional blocks in HIV-1 latency. Post-transcriptional blocks of the nuclear export of various viral transcripts including unspliced, partially spliced, multiply-spliced, and translation of HIV-1 RNA by miRNAs have also been reported (Pomerantz et al., 1990; Malim and Cullen, 1991; Lassen et al., 2006; Weng et al., 2014; Modai et al., 2019). Interestingly, a recent study from the group of Alessandro Marcello has demonstrated that the expression level of MATR3 and PSF, two known posttranscriptional cofactors of the HIV-1 protein Rev required for Rev-mediated export of RRE-containing HIV-1 RNAs (Kula et al., 2011, 2013), are poorly expressed in latently-infected patients cells (Sarracino et al., 2018), suggesting a novel posttranscriptional block linked to RNA export. This latter block was reversed by ectopic overexpression of MATR3 which boosted the action of the HDAC inhibitor SAHA in the J-Lat cell line model for HIV-1 latency (Sarracino et al., 2018). These results demonstrated the importance of post-transcriptional blocks, especially at the level of viral RNAs export, that need to be relieved to reach full viral reactivation by LRAs. Similarly, the work of Andrew Mouland and colleagues has demonstrated that UPF-1, a known RNA surveillance protein (Ajamian et al., 2015), acts as a positive post-transcriptional regulator of viral reactivation from latency (Rao et al., 2018).

Additional post-transcriptional mechanisms including the involvement of cellular miRNA and non-coding RNAs in latency have been described. More specifically, the regulation of viral expression and production by miRNAs targeting PCAF (Triboulet et al., 2007) and CyclinT1 (Sung and Rice, 2009; Budhiraja et al., 2013) have been related to latency (Huang et al., 2007). Many of these miRNAs involved in this process are expressed in resting cells but are downregulated during T-cell activation (Huang et al., 2007). For instance, the lower susceptibility to HIV-1 infection of monocytes in comparison to macrophages has been shown to be correlated with high and low expression of these miRNAs, respectively (Klase et al., 2007). Finally, lncRNA called NRON which is strongly expressed in resting $\mathrm{CD}^{+} \mathrm{T}$ cells was shown to be involved in HIV-1 latency by inducing Tat degradation through the proteasome pathway ( $\mathrm{Li}$ et al., 2016). The combination of SAHA with NRON knockdown significantly reactivates viral production from latently-infected primary $\mathrm{CD}^{+} \mathrm{T}$ cells (Li et al., 2016).

Altogether, the complexity of the molecular mechanisms underlying HIV-1 latency marks the heterogeneous nature of the HIV-1 reservoirs.

\section{SHOCK AND KILL STRATEGY TO ELIMINATE THE LATENT RESERVOIR}

Mechanistic insights into HIV-1 transcriptional repression during latency have allowed to develop the "shock and kill" strategy. This approach is based on the use of small-size chemical compounds called LRAs which reactivate HIV-1 from latency (the "shock" phase) while maintaining ART in order to prevent new infection events (Sengupta and Siliciano, 2018).
This kind of strategy would allow the "kill" phase during which latently-infected cells would then die from viral cytopathic effects or host cytolytic effector mechanisms following viral reactivation. Of note, this strategy does not discriminate between replication-competent and defective proviruses. Several classes of LRAs have been developed and studied (reviewed in Kim et al., 2018; Spivak and Planelles, 2018; Sadowski and Hashemi, 2019). These include: PKC agonists, MAPK agonists, CCR5 antagonist, Tat vaccine, SMAC mimetics, inducers of $\mathrm{P}-\mathrm{TEFb}$ release, activators of Akt pathway, benzotriazole derivatives, epigenetic modifiers (including HDACis, HMTis, and DNMTis), and immunomodulatory LRAs (including TLR agonists, IL15 agonist and immune checkpoint inhibitors) (summarized in Table 1).

It has been further demonstrated by several groups, including ours, that targeting a single mechanism might not be efficient enough to reactivate the majority of latent proviruses and that combinations of LRAs acting on several HIV-1 silencing molecular mechanisms are needed to obtain synergistic viral reactivations and achieve a more significant decrease in the size of the reservoirs (Reuse et al., 2009; Bouchat et al., 2012, 2016; Darcis et al., 2015; Jiang et al., 2015; Laird et al., 2015; Pache et al., 2015; Tripathy et al., 2015; Abdel-Mohsen et al., 2016; Chen et al., 2017; Rochat et al., 2017; Das et al., 2018). Moreover, when LRAs are used in combination, lower concentrations are effective, thereby reducing the toxicity of each LRA. However, even if these LRA combinations reverse latency, they could inhibit multiple $\mathrm{CD}^{+} \mathrm{T}$ cell function [reviewed in Clutton and Jones (2018)]. Importantly, despite the potent effect of a single LRA and of LRA combinations in vitro and ex vivo, multiple clinical trials have failed to show a decrease in the size of the latent reservoir in vivo. A clear change in plasma HIV-1 RNA with a subsequent decrease in the reservoir size in vivo has been seen only for the immune check point inhibitor nivolumab (Guihot et al., 2018) and for romidepsin (combined with an immunovaccine) (Leth et al., 2016) but without prolonging time to viral rebound after ART interruption in this latter study (Leth et al., 2016). In the case of nivolumab, the study was conducted only on one patient who experienced a drastic and sustained decrease of the HIV1 reservoir (Guihot et al., 2018). However, other controversial studies found no consistent changes in the size of the latent reservoir nor in HIV-specific CD8 ${ }^{+}$T-cell responses in HIV-1infected individuals treated with anti-PD1 antibodies (including nivolumab) (Le Garff et al., 2017; Evans et al., 2018; Lavolé et al., 2018; Scully et al., 2018). Success to completely eradicate latent viruses with LRAs is hampered by the heterogeneous nature of the latent reservoir and by the diversity of the silencing mechanisms governing latency that make the current "shock and kill" strategy inefficient.

\section{LATENCY REVERSING AGENTS HIGHLIGHT THE HETEROGENEOUS NATURE OF THE LATENT RESERVOIR}

All studies investigating LRAs have demonstrated the heterogeneous nature of the cellular and tissue reservoirs of 
TABLE 1 | Classes of HIV-1 latency reversing agents.

\begin{tabular}{|c|c|c|c|}
\hline LRA classes & Examples & Targets & References \\
\hline PKC agonists & $\begin{array}{l}\text { Prostratin Bryostatin-1 Ingenols: Ingenol-B, } \\
\text { Ingenol 3,20-dibenzoate (Ingenol-db), } \\
\text { ingenol-3-angelate (ingenol mebutate, PEP005) }\end{array}$ & $\mathrm{NF}-\kappa \mathrm{B}$ activation & $\begin{array}{l}\text { Kulkosky et al., 2001; DeChristopher et al., 2012; Jiang } \\
\text { et al., 2014; Darcis et al., 2015; Spivak et al., } 2015\end{array}$ \\
\hline MAPK agonist & Procyanidin trimer C1 & MAP Kinase activation & Cary and Peterlin, 2018 \\
\hline CCR5 antagonist & Maraviroc & $N F-\kappa B$ activation & López-Huertas et al., 2017; Madrid-Elena et al., 2018 \\
\hline Tat vaccine & $\begin{array}{l}\text { Tat Oyi vaccine } \\
\text { Tat-R5M4 protein }\end{array}$ & Activation of HIV-1 LTR & Geng et al., 2016 \\
\hline SMAC mimetics & $\begin{array}{l}\text { SBI-0637142 } \\
\text { Birinapant }\end{array}$ & $\begin{array}{l}\text { Induction of non-canonical } \\
\text { NF-кB pathways }\end{array}$ & Pache et al., 2015; Hattori et al., 2018 \\
\hline Inducers of P-TEFb release & $\begin{array}{l}\text { BETis: JQ1, I-BET, I-BET151, OTX015, } \\
\text { UMB-136, MMQO, CPI-203, RVX-208, PFI-1, } \\
\text { BI-2536 and BI-6727 } \\
\text { HMBA }\end{array}$ & Release of P-TEFb & $\begin{array}{l}\text { Contreras et al., 2007; Bartholomeeusen et al., 2012; } \\
\text { Darcis et al., 2015; Lu et al., 2016; Huang et al., 2017; } \\
\text { Lu et al., 2017; Abner et al., 2018; Gohda et al., 2018; } \\
\text { Liang et al., } 2019\end{array}$ \\
\hline Activators of Akt pathway & Disulfiram & $\begin{array}{l}\text { Upregulation of Akt } \\
\text { signaling pathway }\end{array}$ & Xing et al., 2011; Doyon et al., 2013; Spivak et al., 2014 \\
\hline Benzotriazole derivatives & 1-hydroxybenzotriazol (HOBt) & STAT5 activation & Bosque et al., 2017 \\
\hline \multirow[t]{3}{*}{ Epigenetic modifiers } & $\begin{array}{l}\text { HDACis: TSA, trapoxin, SAHA, romidepsin, } \\
\text { panobinostat, entinostat, givinostat, valproic acid, } \\
\text { MRK-1/11, AR-42, fimepinostat, chidamide }\end{array}$ & HDAC inhibition & $\begin{array}{l}\text { Van Lint et al., 1996; Quivy et al., 2002; Ylisastigui } \\
\text { et al., 2004; Archin et al., 2009; Archin et al., 2012; } \\
\text { Rasmussen et al., 2013, 2014; Wightman et al., 2013; } \\
\text { Mates et al., 2015; Søgaard et al., 2015; Banga et al., } \\
\text { 2016a; Kuai et al., 2018; Gunst et al., 2019; Yang et al., } \\
2018\end{array}$ \\
\hline & $\begin{array}{l}\text { HMTis: chaetocin, EPZ-6438, GSK-343, DZNEP, } \\
\text { BIX-01294, UNC-0638 }\end{array}$ & Suv39H1, G9a, SMYD2 & $\begin{array}{l}\text { Friedman et al., 2011; Bouchat et al., 2012; Nguyen } \\
\text { et al., } 2017\end{array}$ \\
\hline & DNMTis: 5-AzaC, 5-AzadC & DNMT1, 3a, 3b & Bouchat et al., 2016 \\
\hline Immunomodulatory LRAs & $\begin{array}{l}\text { TLR agonists: TLR2 (Pam3CSK4), TLR7 } \\
\text { (GS-9620), TLR8, TLR9 (MGN 1703) agonists } \\
\text { IL-15 agonist (ALT-803) } \\
\text { Immune checkpoint inhibitors: anti-PD-1 } \\
\text { (nivolumab, pembrolizumab), anti-CTLA-4 } \\
\text { (ipilimumab) }\end{array}$ & & $\begin{array}{l}\text { Schlaepfer and Speck, 2011; Novis et al., 2013; } \\
\text { Wightman et al., 2015; Jones et al., 2016; Offersen } \\
\text { et al., 2016; Tsai et al., 2017; Evans et al., } 2018\end{array}$ \\
\hline
\end{tabular}

latent HIV-1 and their diverse reactivation capacity, highlighting the different determinant responsible for the heterogeneous responses to LRAs. All these studies are summarized in Table 2.

\section{HIV-1 Diversity Within the Latent and Reactivated Reservoirs}

Few studies so far have focused on investigating the contribution of the viral diversity, the compartmentalization, the intact or defective nature of the viral reservoir, and the origin of the rebounding virus in latency reversal. A previous study in patients who initiated ART during acute infection showed that proviral sequences from PBMCs and GALT presented low level of genomic diversity and divergence and remained unchanged after treatment interruption (Lerner et al., 2011). Moreover, there was no phylogenetic link between the rebounded plasma viral sequences and those from the GALT proviral DNA, indicating that HIV-1 cellular reservoirs in the GALT may be different from those circulating in peripheral blood and might not contribute to the rebounded plasma viremia (Lerner et al., 2011). Other studies have supported the compartmentalization idea of the viral population in the gut with divergent opinions (van der Hoek et al., 1998; Lewis et al., 2013; Rozera et al., 2014). Depending on the stage of HIV-1 infection, the diversity of HIV-1 RNA appears lower in patients with early infection versus chronic infection, and thus, compartmentalization is lost during chronic infection (Rozera et al., 2014). However, other works have supported other conflicting ideas with findings showing absence of compartmentalization of HIV-1 between the gut and blood (Avettand-Fenoel et al., 2011; Imamichi et al., 2011; Evering et al., 2012), providing evidence for cross infection between these two compartments (Chun et al., 2008).

HIV-1 sequence diversity has been reported to be either higher (Klein et al., 2018) or similar (Piantadosi et al., 2019) to genital tract compared to blood. Viral compartmentalization between the blood and the male genital tract has been reported by multiple studies including SIV-infected macaques (Delwart et al., 1998; Paranjpe et al., 2002; Pillai et al., 2005; Coombs et al., 2006; Diem et al., 2008; Houzet et al., 2018). More recently, patients under suppressive ART exhibited a significant positive correlation between viral diversity and genetic compartmentalization in the blood and testes, but it was attributable to differential frequencies of identical HIV-1 sequences between the two sites (Miller et al., 2019). However, there was no evidence of compartmentalization when only unique sequences per sites are considered, suggesting that compartmentalization between blood and testes is linked to clonal expansion (Miller et al., 2019).

HIV-1 phylogenetic analysis of post-mortem CSF, brain, and spleen from HIV-1 patients under ART and presenting dementia symptoms showed that HIV-1 strains from the blood 
TABLE 2 | The diverse responses of latently-infected cells to LRAs reflect the heterogeneity of the mechanisms driving HIV-1 latency.

\begin{tabular}{|c|}
\hline Heterogeneity \\
\hline
\end{tabular}

ras

\begin{tabular}{|c|c|c|c|c|}
\hline & & & & LRAs \\
\hline Virus genetic background & Norton et al., 2019 & $\begin{array}{l}\text { Jurkat cells infected with HIV-1 WT } \\
\text { or mutated in ESE }\end{array}$ & Flow cytometry & $\begin{array}{l}\text { PMA } \\
\text { JQ1 } \\
\text { Panobinostat }\end{array}$ \\
\hline Cell model & Spina et al., 2013 & $\begin{array}{l}\text { J-Lat } 6.3,8.4,11.1 \text { and } 5 \mathrm{~A} 8 . \\
\text { Primary T-cell models of HIV-1 } \\
\text { latency. } \\
\text { Ex vivo T-cell cultures from } \mathrm{HIV}^{-1}{ }^{+} \\
\text {individuals. }\end{array}$ & $\begin{array}{l}\text { Flow cytometry } \\
\text { QVOA }\end{array}$ & $\begin{array}{l}\text { Anti-CD3 + anti-CD28, } \\
\text { PHA, PMA, prostratin, } \\
\text { bryostatin, } \\
\text { PMA + ionomycin, TNF } \alpha \text {, } \\
\text { IL-7 + IL-2, SAHA, MRK-1, } \\
\text { MRK-11, HMBA, ionomycin }\end{array}$ \\
\hline Cell type & $\begin{array}{l}\text { Grau-Expósito } \\
\text { et al., } 2019\end{array}$ & $\begin{array}{l}\text { Patient-derived diverse subsets of } \\
\text { memory } \mathrm{CD} 4^{+} \mathrm{T} \text { cells. }\end{array}$ & Flow-based RNA FISH & $\begin{array}{l}\text { Romidepsin } \\
\text { Panobinostat } \\
\text { JQ1 } \\
\text { Ingenol-3-angelate } \\
\text { Bryostain-1 }\end{array}$ \\
\hline
\end{tabular}

LRAs

Mutations altering viral gene splicing (tat $m R N A)$ lead to more silent phenotypes that are differently reactivated by diverse LRAs.

None of the in vitro T cell model alone is able to capture accurately the ex vivo response characteristics of latently-infected T cells isolated from $\mathrm{HIV}^{+}$individuals.

\begin{tabular}{|c|c|c|c|c|}
\hline & Kulpa et al., 2019 & $\begin{array}{l}\text { Ex vivo T-cell cultures from } \mathrm{HIV}-1^{+} \\
\text {individuals and in vitro model of } \\
\text { HIV-1 latency LARA. }\end{array}$ & $\begin{array}{l}\text { Flow cytometry } \\
\text { Cell sorting } \\
\text { TILDA }\end{array}$ & $\begin{array}{l}\text { Bryostatin } \\
\text { IL-15 } \\
\text { PMA + ionomycin }\end{array}$ \\
\hline & Baxter et al., 2016 & $\begin{array}{l}\text { Diverse subsets of patient-derived } \\
\mathrm{CD}^{+} \mathrm{T} \text { cells. }\end{array}$ & Flow-based RNA FISH & $\begin{array}{l}\text { Bryostatin-1 } \\
\text { Ingenol-3-angelate }\end{array}$ \\
\hline & Kula et al., 2019 & $\begin{array}{l}\text { U1, THP89, CHME5 and J-Lat 9.2, } \\
\text { J-Lat A1 and A2. }\end{array}$ & Flow cytometry & Disulfiram \\
\hline $\begin{array}{l}\text { Latency molecular } \\
\text { mechanisms }\end{array}$ & Yukl et al., 2018 & Patient-derived blood $\mathrm{CD} 4^{+} \mathrm{T}$ cells. & RT-ddPCR & $\begin{array}{l}\text { Panobinostat } \\
\text { Romidepsin } \\
\text { Ingenol mebutate }\end{array}$ \\
\hline Tissue reservoir & Elliott et al., 2014 & $\begin{array}{l}\text { Patient-derived blood and rectal } \\
\mathrm{CD}^{+} \mathrm{T} \text { cells. }\end{array}$ & Semi-nested RT-qPCR & SAHA \\
\hline $\begin{array}{l}\text { Integration site of the } \\
\text { provirus and chromatin } \\
\text { context }\end{array}$ & Chen et al., 2017 & Jurkat cells infected with B-HIVE. & $\begin{array}{l}\text { Sorting of the GFP }{ }^{+} \text {cells } \\
\text { coupled with inverse PCR and } \\
\text { provirus mapping }\end{array}$ & $\begin{array}{l}\text { PHA } \\
\text { SAHA }\end{array}$ \\
\hline
\end{tabular}

Romidepsin acts on majority of the T-cell subsets $\left(T_{C M}\right.$, $T_{E M}, T_{T M}$, and $T_{N A}$ ) except for $T_{S C M}$.

Ingenol reactivates majority of $\mathrm{T}$-cell subsets ( $T_{\mathrm{NA}}$,

$T_{S C M}, T_{C M}$, and $T_{T M}$ ) except for $T_{E M}$.

Panobinostat acts mainly on $T_{C M}$ and slightly on $T_{E M}$ and $\mathrm{T}_{\mathrm{NA}}$.

Bryostatin-1 reactivates very modestly $T_{\mathrm{NA}}, T_{\mathrm{TD}}$, and $\mathrm{T}_{\mathrm{CM}}$

JQ1 acts very modestly on the majority of the subsets, except for $T_{S C M}$

Romidepsin + ingenol is the most potent combination generating p24 only in $\mathrm{T}_{\mathrm{CM}}$.

$T_{C M}$ cells differentiate into $T_{E M}$ cells when exposed to LRAs.

The increase of $T_{E M}$ subset frequencies is predictive of higher prevalence of cells carrying an inducible reservoir.

Bryostatin-1 mainly reactivates $T_{E M}$. Ingenol reactivates $\mathrm{T}_{\mathrm{CM}}, \mathrm{T}_{\mathrm{TM}}$ and $\mathrm{T}_{\mathrm{EM}}$.

Disulfiram reactivates HIV-1 in 3 myeloid infected cell lines but not in the infected T-lymphoid cell lines.

Panobinostat and romidepsin increase full-length and elongated transcripts, while ingenol mebutate increases polyadenylated and multiply spliced transcripts.

Fold change in CA-US HIV-1 RNA following SAHA is 5 times higher in $\mathrm{CD}^{+}{ }^{+} \mathrm{T}$ cells from blood compared to rectal tissue from $\mathrm{HIV}-1^{+}$individuals.

PHA and SAHA reactivate proviruses located at distinct integration sites but with an increased frequency in the proximity of enhancers for SAHA. 
TABLE 2 | Continued

$\begin{array}{llll}\text { Heterogeneity References } \quad \text { Cellular or tissue reservoir Methodology } & \text { Heteneous responses to LRAs }\end{array}$

Methodology

Heterogeneous responses to LRAs

LRAs

Abner et al., $2018 \quad$ Jurkat cells infected with

B-HIVE.

Sorting of the $\mathrm{GFP}^{+}$cells

coupled with RT-qPCR and

provirus mapping

JQ1

SAHA

Prostratin

Battivelli et al.

Primary $\mathrm{CD} 4^{+} \mathrm{T}$ cells infected

Cells sorting coupled with

semi-nested

Panobinostat

2018 with dual-labeled HIV-1.

ligation-mediated PCR and Bryostatin-1

provirus sequencing Anti-CD3 + anti-CD28

Patient to patient Das et al., 2018 Patient-derived resting memory EDITS

and patient gender

Anti-CD3 + anti-CD28

SAHA

Darcis et al., 2017

Patient-derived $\mathrm{CD}^{+}{ }^{+}$-depleted

Highly sensitive TaqMan

JQ1 + bryostatin

PBMCs and resting $\mathrm{CD}^{+}{ }^{+} \mathrm{T}$

based RT-qPCR

JQ1 + ingenol-B

cells.

5-AzadC + panobinosta

5-AzadC + romidepsin

Yukl et al., $2018 \quad$ Patient-derived CD4 ${ }^{+}$T cells. RT-ddPCR

JQ1, Disulfiram

Chaetocin, Panobinostat

Romidepsin, Ingenol mebutate

Ingenol 3,20-dibenzoate

B-HIVE, barcoded HIV ensembles; CA-US RNA, cell-associated unspliced RNA; EDITS, envelope detection by induced transcription-based sequencing; LARA, latency and reversion assay; RNA FISH, RNA Fluorescence In Situ Hybridization; RT-ddPCR, reverse transcription droplet digital polymerase chain reaction; TILDA, Tat/rev-induced limiting dilution assay; QVOA, Quantitative Viral Outgrowth Assays.

BETi (MMQO and JQ1) target viruses integrated at distinct sites

as compared to those targeted by SAHA and prostratin.

LRAs reactivate only $5 \%$ of latently-infected cells. The inducible and non-inducible populations exhibit distinct chromatin

integration sites which were associated, respectively, with active chromatin and heterochromatin with non-accessible region.

Women have reduced inducible RNA reservoirs compared to men following treatment with anti-CD3 + anti-CD28.

ESR-1 antagonists potentiate HIV-1 reactivation by SAHA however, females show higher reactivation than males $\mathrm{HIV}-1^{+}$ individuals.

There is a positive correlation between the HIV-1 reservoir size and the ex vivo capacity of HIV-infected patient cell cultures to be reactivated by LRAs. However, some HIV-1+ patients deviate from this linearity (for example, patients who, despite a low reservoir, are more easily reactivated than many other patients who have a larger reservoir).

All LRAs exhibit inter-patient variability to reverse the blocks to HIV-1 transcription with a very weak exception for romidepsin. 
and spleen are different from those in the brain and CSF (Caragounis et al., 2008). A more recent study of env and nef phylogeny on ART suppressed individuals confirmed the presence of considerable viral diversity in the spleen and lymph nodes (Nolan et al., 2018). However, there is no viral compartmentalization between spleen and PBMCs in SIVinfected and suppressed rhesus macaques (Siddiqui et al., 2019).

The comparison of latent HIV-1 from the blood and lymph node $\mathrm{CD}^{+}{ }^{+} \mathrm{T}$ cells from HIV-1 individuals undergoing ART interruption, after TLR9 coadministration with ART, suggests the same frequencies of intact proviruses in the blood and lymph nodes and the fact that $\mathrm{CD}^{+}{ }^{+} \mathrm{T}$ cells carrying latent viruses circulate between the blood and lymphoid tissues. However, there is no overlap between latent reservoirs and rebounded virus, thereby supporting the idea that recombinations may play a role in the emergence of the rebounded viremia (Vibholm et al., 2019).

Time to ART from estimated date of infection as an early ART initiation is associated with less molecular diversity in CSF without impacting HIV-1 DNA provirus compartmentalization in the CNS which occurs very early after infection (Schnell et al., 2010; Sturdevant et al., 2015; Oliveira et al., 2017). In the study of Oliveira et al. (2017), a higher diversity in PBMCs than in CSF is reported. The compartmentalized HIV1 RNA in CNS is found to contribute to viral rebound within the CSF in patients undergoing treatment interruption but is phylogenetically distinct from those present in the paired blood plasma (Gianella et al., 2016).

Most of the previous studies estimated that blood memory $\mathrm{CD}^{+} \mathrm{T}$ cells are the source of viral rebound after ART interruption or viral reactivation from latency. The first work of Timothy Schacker and colleagues examined HIV-1 variants by single-genome amplification and phylogenetic analyses in matched lymph nodes, GALT biopsies and blood from HIV-1 suppressed individuals under longstanding ART after treatment interruption (Rothenberger et al., 2015). The rebounded virus after treatment interruption was found to be detectable in latently-infected cells at multiple sites with a highly complex and genetically diverse population of virions which bring out the challenges facing the heterogeneity of HIV-1 reservoir (Rothenberger et al., 2015). Another study of the effect of a brief treatment interruption on the HIV-1 latent reservoir of individuals who initiated ART during chronic infection showed no alteration either in the size or in the diversity of the peripheral reservoir and highlighted the substantial variability and the prevalence of clonally-expanded viral populations (Salantes et al., 2018). Interestingly, the group of Sarah Palmer indicated that analytical treatment interruption (ATI) activated proviruses with similar sequence between plasma and intestinal lamina propria mononuclear cells (Barton et al., 2016), indicating that intestinal HIV-1 reservoir is contributing to viremia following ATI. A recent study by the group of Linos Vandekerckhove confirmed the heterogeneous source of viral rebound from distinct anatomical reservoirs in HIV-1 individuals undergoing treatment interruption, showing that genetically-identical viral expansions play a significant role in viral rebound (De Scheerder et al., 2019). In a study presented by Oliveira et al. (CROI 2019,
Poster 327-Characterizing the HIV DNA reservoirs in wholebody tissues in the "Last Gift" cohort), HIV-1 DNA was detected in most body tissues with a nice distribution and compartmentalization of HIV-1 reservoir between tissues from the Last Gift cohort enrolling altruistic, terminally-ill persons living with HIV-1. They have successfully sequenced env from 10 different tissues with many identical HIV-env sequences sampled in multiple body tissues.

Some LRA interventions analyzed whether the increase of CAUS HIV-1 RNA is related to limited or to broad activation of HIV-1 proviruses. The single genome sequencing of viral RNA transcripts showed that panobinostat and vorinostat activate genetically diverse $\mathrm{HIV}-1$ proviruses that are similar to that observed during ATI but with a high percentage of defective viral sequences (Barton et al., 2016). More precisely, $\mathrm{T}_{\mathrm{CM}}$ contributed to the rebounded viremia, indicating once again the important role of this subset in the persistence of latent HIV-1 (Barton et al., 2016). Finally, romidepsin administration to HIV-1 individuals under suppressive ART activates transcription from blood CD4 ${ }^{+}$ T cells latent HIV-1 proviruses (Winckelmann et al., 2017). Importantly, the viremia induced by romidepsin contained few defective mutations and is characterized by low genetic diversity (Winckelmann et al., 2017, 2018).

Together, these studies illustrate that cure strategies should consider the complex and variable composition of the different viral reservoirs, the replication-competent capacity, the diversity and compartmentalization of HIV-1 reservoir, and the role of cellular clonal expansion and cellular proliferation in promoting HIV-1 persistence.

\section{Weak Reactivation Potential of Latency Reversing Agents and Post-transcriptional Blocks}

An important issue for the development of a more effective "shock and kill" approach is to determine how effective LRAs are in terms of full viral reactivation from all latently-infected cells composing the reservoirs. Indeed, most of the in vivo reactivation studies demonstrated a rather weak reactivation effect of LRAs, i.e., an effect only on HIV-1 transcription with much less or no effect on plasma HIV-1 RNA (Archin et al., 2012; Spivak et al., 2014; Elliott et al., 2015). For instance, a recent clinical trial using escalating doses of disulfiram demonstrated that even if all doses produced an increase in the level of intracellular HIV-1 RNA, only the highest dose increased plasma HIV-1 RNA level albeit with very low effect (Elliott et al., 2015). Similar observations have been reported for SAHA: i.e., weak effect at the level of viral particle production in vivo as assessed by measurement of plasma HIV-1 RNA (Archin et al., 2012). Mohammadi et al. (2014) have shown in their primary $\mathrm{CD}^{+} \mathrm{T}$ cell models that disulfiram and SAHA treatments increased viral transcription, but failed to effectively enhance viral translation. In addition, the group of Maria Buzon has very recently demonstrated that a median of $16.28 \%$ of the whole HIV-reservoir exhibited HIV-1 transcripts induction after viral reactivation using various LRAs and their combinations, but only $10.10 \%$ of these HIV-1 RNA ${ }^{+}$ cells produced viral p24 proteins (Grau-Expósito et al., 2019). 
Recent work by the group of Andrew Lever (Norton et al., 2019) has demonstrated that inefficient splicing regulation may also influence the action of LRAs. They studied the polymorphisms occurring in a recently identified viral mRNA splicing regulatory element $\left(\mathrm{ESE}_{\mathrm{tat}}\right)$ regulating tat mRNA splicing which results in more silent phenotypes of the virus. Indeed, higher doses of LRAs (PMA, JQ1, and panobinostat) were required to reactivate silent viruses bearing the polymorphisms in $\mathrm{ESE}_{\mathrm{tat}}$, reflecting their lower rate of inducibility as compared to wild-type HIV1 (Norton et al., 2019). Therefore, different post-transcriptional mechanisms including blocks to export and alteration of mRNA splicing may be considered as druggable targets for a combined approach of more potent latency reversal (Sarracino et al., 2018; Norton et al., 2019).

\section{Cell Model-Specific Effects of Latency Reversing Agents}

Latency reversing agents were shown to be cell model-specific exhibiting diverse reactivation profiles across multiple HIV-1 latency model systems. A comprehensive study by Spina et al. (2013) tested the potency of a panel of thirteen LRAs for their ability to reactivate HIV-1 in several broadly used HIV-1 latency models (primary T-cell models, multiple J-Lat cell lines, and ex vivo T-cell cultures derived from the blood of HIV$1^{+}$individuals) (Spina et al., 2013). They showed that PHA was the only stimulus that uniformly reactivated latent HIV1 in all these cell models, although other LRAs exerted largely heterogeneous responses among the various models (Spina et al., 2013). Importantly, following LRA treatment, none of the in vitro cell model systems could accurately capture the ex vivo response characteristics of latently-infected $\mathrm{T}$ cells from patients.

\section{Cell Type-Specific Effects of Latency Reversing Agents}

In addition to cell model-specific effects of LRAs, recent studies demonstrated the cell type-specific effects of LRAs. For instance, Baxter et al. (2016) highlighted heterogeneous responses of CD4 ${ }^{+}$ populations to bryostatin and ingenol. The authors showed that bryostatin induced HIV-1 expression in $\mathrm{T}_{\mathrm{EM}}$ cells but had limited effect in $\mathrm{T}_{\mathrm{CM}}$ and $\mathrm{T}_{\mathrm{TM}}$ cells. While ingenol, on the other hand, exhibited more similar reactivation effects among the different memory T-cell subpopulations (Baxter et al., 2016). Similarly, the group of Maria Buzon has very recently demonstrated heterogeneous responses to LRAs of the latent reservoirs present in different $\mathrm{CD}^{+}$T-cell subpopulations (Grau-Expósito et al., 2019). Romidepsin and ingenol and their combination were the most potent LRAs at reactivating HIV-1 in almost all the subsets of $\mathrm{CD}^{+} \mathrm{T}$ cells by increasing, respectively, the proportion of $\mathrm{T}_{\mathrm{CM}}, \mathrm{T}_{\mathrm{EM}}, \mathrm{T}_{\mathrm{TM}}, \mathrm{T}_{\mathrm{NA}}$, and $\mathrm{T}_{\mathrm{NA}}, \mathrm{T}_{\mathrm{SCM}}, \mathrm{T}_{\mathrm{CM}}$, $\mathrm{T}_{\mathrm{TM}}$ cells expressing HIV-1 RNA. Panobinostat successfully reactivated HIV-1 only in $\mathrm{T}_{\mathrm{CM}}$ cells. Bryostatin-1 reactivated very modestly some $\mathrm{T}$-cell subsets, including $\mathrm{T}_{\mathrm{NA}}, \mathrm{T}_{\mathrm{TD}}$, and $\mathrm{T}_{\mathrm{CM}}$. Therefore, T-cell differentiation status may impact the action of LRAs. Indeed, Kulpa et al. (2019) show in ex vivo and in vitro models that differentiated phenotype of $\mathrm{T}_{\mathrm{EM}}$ cells from that of quiescent $\mathrm{T}_{\mathrm{CM}}$ cells is associated with a potentiated response to LRAs and to a highest level of inducible HIV-1 reservoir. Additionally, the effects may also be cell type-specific. We have also recently demonstrated that disulfiram exhibited limited reactivation spectra, being active only in myeloid-derived HIV-1 latently infected cell lines (U1, THP89GFP monocytic, and CHME-5/HIV-1 microglial cells) but not in Jurkat-based T-cell lines (Kula et al., 2019). These heterogeneous cellular responses to LRAs indicate that distinct and cell-type dependent molecular mechanisms contribute to HIV-1 latency in diverse reservoirs.

\section{Latency Molecular Mechanism-Specific and Tissue-Specific Effects of Latency Reversing Agent}

It has recently been demonstrated by Yukl et al. (2018), using an elegant transcriptional profiling approach, that LRAs exhibit silencing mechanisms-specific effects. These authors found that HDACis (panobinostat and romidepsin) and PKC agonists (ingenol 3,20-dibenzoate and ingenol mebutate) exert differential effects on the latency blocks in the blood latentlyinfected $\mathrm{CD}^{+}{ }^{+} \mathrm{T}$ cells (Yukl et al., 2018). More specifically, HDACis increased total and elongated transcripts but had less or no effect on polyadenylated and multiply spliced transcripts, whereas ingenol mebutate strongly induced polyadenylated and multiply spliced transcripts but had lesser effects on transcription initiation and elongation (Yukl et al., 2018). These latter results are in agreement with another study showing that romidepsin administration after six doses of the therapeutic vaccine Vacc$4 \mathrm{x}$, in HIV-1 individual under suppressive ART, increased early events in HIV-1 transcription (initiation and elongation) but had less effect on later stages (completion, multiple splicing) (Moron-Lopez et al., 2019). The differential effects of these LRAs suggest that the mechanisms underlying the blocks to completion and splicing may differ from those that mediate the blocks to initiation and elongation. The group of Yukl compared CD4 ${ }^{+}$ $\mathrm{T}$ cells from the blood and rectum tissue reservoirs using a similar transcriptional profiling approach and found a much greater block to HIV-1 transcription initiation in the rectum compared to blood (Telwatte et al., 2018). Indeed, the ratio of total to elongated transcripts was 6-fold lower in the rectum $\mathrm{CD}^{+}{ }^{+} \mathrm{T}$ cells, suggesting less of a block to HIV-1 transcriptional elongation in rectal $\mathrm{CD}^{+}{ }^{+} \mathrm{T}$ cells (Telwatte et al., 2018). In fact, a multi-dose trial of SAHA has evidenced that the cell-associated HIV-1 RNA in latently infected CD $4^{+} \mathrm{T}$ cells from the blood was 5-fold higher compared to $\mathrm{CD} 4^{+} \mathrm{T}$ cells from the rectal tissue (Elliott et al., 2014), suggesting that the LRA-driven effects may also be tissue-specific. Thus, further studies should investigate whether gut cells differ from blood cells in their response to LRAs in terms of HIV-1 transcript production and of cellular gene expression.

\section{Integration Site-Specific Effects of Latency Reversing Agents}

The group of Guillaume Fillion demonstrated that different LRAs reactivate different subsets of latent proviruses (Chen et al., 2018). Using a method called B-HIVE to map the chromosomal locations of individual proviruses, these authors 
revealed in Jurkat cells that responses to LRAs are also viral integration site-specific. They found that PHA and SAHA reactivated proviruses inserted at distinct genomic locations, suggesting that the insertion context of HIV-1 is a critical determinant of the viral response to LRAs (Chen et al., 2018). Using the same B-HIVE technology, the groups of Albert Jordan and Guillaume Fillion demonstrated that MMQO (an LRA which acts as an I-BET) and JQ1 reactivate latent HIV1 proviruses integrated at distinct sites from those proviruses targeted by SAHA and prostratin (Abner et al., 2018). Interestingly, Battivelli et al. (2018) demonstrated that only less than $5 \%$ of latently-infected primary $\mathrm{CD}^{+} \mathrm{T}$ cells are reactivated by LRAs. By further sequencing analysis, these authors showed the preference toward integration events in active chromatin sites for the reactivable cell population, while these regions were significantly disfavored in the nonreactivable group, highlighting that the role of chromatin environment is an important determinant of LRA effectiveness (Battivelli et al., 2018).

\section{Patient-Specific and Sex-Specific Effects of Latency Reversing Agents}

Many other determinants may also be responsible for the heterogeneous reactivation profile of LRAs. Patient-dependent effects of LRAs were reported. Indeed, viral productions evident in some patients but not in others were observed in all reactivation clinical trials (Spivak et al., 2014; Elliott et al., 2015; Leth et al., 2016; Tapia et al., 2017). Additionally, in our previous reactivation studies, we demonstrated patient-specific variations in terms of reactivation capacity of their ex vivo cell cultures following treatments with various LRAs (Darcis et al., 2015, 2017; Bouchat et al., 2016). Indeed, we established a positive correlation between the size of the HIV-1 reservoirs and the ex vivo capacity of HIV-1-infected patients' cell cultures to be reactivated by LRAs (Darcis et al., 2017), but we identified HIV$1^{+}$patients who deviated from this linearity relative to their corresponding HIV reservoir size (Darcis et al., 2017), indicating that the reservoirs size is one determinant of the cell capacity to produce virus but that this parameter alone is not sufficient. The patient-dependent heterogeneity in the responses to LRAs could be explained by patient characteristics such as genetic background, time to treatment initiation, duration and type of therapy and also by the gender-specificity, as recently proposed by the team of Jonathan Karn (Das et al., 2018). Sex-based differences in HIV-1 reservoir activity is characterized by a higher cell-associated HIV-1 RNA, higher plasma HIV-1 RNA, higher T-cell activation, and PD-1 expression in men compared to women (Scully et al., 2019). The group of Jonathan Karn has shown that the estrogen receptor-1 (ESR-1) is a key regulator of HIV-1 latency (Das et al., 2018). More specifically, antagonists of ESR-1 activate latent HIV-1 proviruses and potentiate HIV-1 reactivation by LRAs such as SAHA, TNF $\alpha$, and IL-15, while ESR1 agonists potently block HIV-1 reactivation. Despite a reduced inducible reservoir compared to men, women showed much higher levels of inhibition in response to TCR stimulation in the presence of ESR-1 agonists but exhibited a higher reactivation in response to ESR-1 antagonists when combined with SAHA than the group of male $\mathrm{HIV}^{+}$individuals (Das et al., 2018). The circadian rhythm is an additional biological process that can affect HIV-1 transcription and reactivation (Chang et al., 2018). The circadian rhythm has been first suggested in the clinical trial testing short term administration of disulfiram (Elliott et al., 2015) as a parameter influencing HIV-1 transcription. The authors find an unexpected large variation in pre-dosing CA-US HIV-1 RNA which was statistically significantly higher immediately prior to the first dose of disulfiram than at the two previous time points without changes in HIV-1 DNA or plasma HIV-1 RNA (Elliott et al., 2015). Indeed, Sharon Lewin and colleagues have subsequently demonstrated a significant time-dependent variation in CA-US HIV-1 RNA in $\mathrm{CD}^{+}{ }^{+} \mathrm{T}$ cells from $\mathrm{HIV}^{+}$individuals on suppressive ART, a variation which is modulated by circadian regulator factors driving transcription from the viral LTR (Chang et al., 2018). Thus, in ex vivo studies, the time of blood collection could affect LRA reactivation potency and should be considered to improve latency reversal.

The multiplicity of mechanisms that regulate HIV-1 latency and the diversity of factors responsible for the heterogeneity of the latent HIV-1 reservoir most likely vary from one patient to the other and even from one cell to the other in a single patient. Indeed, several single-cell studies reported cell-to-cell variability of the latent reservoir (Baxter et al., 2016; Yucha et al., 2017) and the heterogeneity of cellular response to LRAs (Passaes et al., 2017). A recent single-cell transcriptome profiling study from Angela Ciuffi laboratory has demonstrated that latently-infected cells are transcriptionally heterogeneous and can be separated into two different cell clusters based on their cellular states (Golumbeanu et al., 2018). These distinct states correlated with the susceptibility to cellular activation and HIV1 reactivation, highlighting that the cellular environment could also contribute to the success of HIV-1 reactivation strategies (Golumbeanu et al., 2018).

\section{CONCLUSION}

In the frame of the "shock and kill" strategy, clinical trials using LRAs have so far produced unconvincing results. This strategy faces multiple barriers which prevent the complete eradication of replication competent viruses of the HIV-1 reservoir and must, therefore, be optimized. Targeting and reactivating latent cells is challenging due to the heterogeneous nature of the viral reservoirs. Recent studies demonstrating diverse responses of infected cells to LRAs point to their weak effect (Archin et al., 2012; Spivak et al., 2014; Elliott et al., 2015) and highlight the diversity of determinants responsible for the reservoirs' heterogeneity that were demonstrated so far to be virus genetic background-(Norton et al., 2019), cell model(Spina et al., 2013), cell type-(Baxter et al., 2016; Grau-Expósito et al., 2019; Kula et al., 2019), silencing mechanism-(Elliott et al., 2014; Yukl et al., 2018), tissue reservoir-(Elliott et al., 2014; Telwatte et al., 2018; Yukl et al., 2018), integration site(Chen et al., 2017; Abner et al., 2018; Battivelli et al., 2018), 
patient-(Darcis et al., 2017; Yukl et al., 2018), and gender(Das et al., 2018) specific. In addition, some studies demonstrate a heterogeneous effect of LRAs on NK cells (Garrido et al., 2016) and cytotoxic T-cell lymphocyte (Walker-Sperling et al., 2016) activity with conflicting observations, suggesting either an immunosuppressive effect or a reduced impact of LRA activity on cells sensing HIV-1 reactivation (Archin et al., 2012; Jones et al., 2014; Clutton et al., 2016; Walker-Sperling et al., 2016; Desimio et al., 2017, 2018). Moreover, prolonged ART treatment is associated with a significant reduction in the frequency of HIV-1-specific CD8 ${ }^{+}$T-cells (Gray et al., 1999; Casazza et al., 2001). Thus, as demonstrated by the group of Robert Siliciano, stimulating HIV-1-specific CTLs prior to reactivating latent HIV1 should be considered for a successful eradication in future clinical trials (Shan et al., 2012). Another determinant of the effectiveness of a given LRA in reactivating and purging the viral reservoirs is its ability to efficiently induce latent HIV-1 by targeting not only transcriptional but also post-transcriptional mechanisms that need to be considered for a combined approach of more potent latency reversal. Additionally, an effective LRA needs to penetrate the multitude of HIV-1 tissue reservoirs and sanctuary sites. For instance, it has been shown that panobinostat did not sufficiently penetrate the central nervous system (Rasmussen et al., 2015) and romidepsin's concentration in CSF of non-human primate was only $2 \%$ of the level found in plasma (Berg et al., 2004). Consequently, ensuring a better tissue penetration of LRAs by enhancing the drug delivery system, and most importantly strengthening the killing of the LRAreactivated cells by stimulating $\mathrm{CD}^{+} \mathrm{T}$ responses are essential for the eradication strategy. Rational design of LRAs considering all these determinants is not possible at the moment, due to the lack of knowledge of all the cellular factors and pathways impacting HIV-1 gene expression and leading to productive viral replication. New approaches including single-cell technologies should be considered to understand why some cells respond to LRAs while others do not as this will be essential for improving the "shock and kill" strategy and hopefully reaching a cure. Moreover, due to the challenges that hinder the effectiveness of the "shock and kill" approach, some attention is also given to strategies aimed at completely suppressing HIV-1 transcription named the "block and lock." In this context, the Tat inhibitor didehydro-cortistatin A (dCA) has shown its ability to inhibit ex vivo residual viral replication under ART and to prolong the

\section{REFERENCES}

Abdel-Mohsen, M., Chavez, L., Tandon, R., Chew, G. M., Deng, X., Danesh, A., et al. (2016). Human galectin-9 is a potent mediator of HIV transcription and reactivation. PLoS Pathog. 12:e1005677. doi: 10.1371/journal.ppat.100 5677

Abdel-Mohsen, M., Kuri-Cervantes, L., Grau-Exposito, J., Spivak, A. M., Nell, R. A., Tomescu, C., et al. (2018). CD32 is expressed on cells with transcriptionally active HIV but does not enrich for HIV DNA in resting T cells. Sci. Transl. Med. 10:eaar6759. doi: 10.1126/scitranslmed.aar6759

Abner, E., Stoszko, M., Zeng, L., Chen, H.-C., Izquierdo-Bouldstridge, A., and Konuma, T. (2018). A new quinoline BRD4 inhibitor targets a distinct latent HIV-1 reservoir for reactivation from other 'shock' drugs. J. Virol. 92:e02056-17. doi: 10.1128/JVI.02056-17 time to viral reactivation after treatment interruption (Kessing et al., 2017), but some in vitro resistance mutations to dCA were reported (Mousseau et al., 2019). Currently, several drugs are identified for their ability to be used as LPA (Latency Promoting Agents) to ensure a functional cure (Suzuki et al., 2013; Wan and Chen, 2014; Vranckx et al., 2016; Hayashi et al., 2017; Jean et al., 2017; Debyser et al., 2018). Undeniably several strategies must be exploited in order to reach a functional cure. Dealing with the residual viremia and the contribution of ongoing viral replication in the reservoir's replenishment is one of the major issues. If one of these strategies is promising its efficacy in clinic will be a long process and should, therefore, lead to the formation of a deep latency state preventing viral rebound after ART interruption.

\section{AUTHOR CONTRIBUTIONS}

AA-A, AK, GD, RV, and CV wrote the manuscript. SD, VG, $\mathrm{PM}, \mathrm{AM}$, and OR gave advice and suggestions for the writing of the manuscript.

\section{FUNDING}

A-AA is a fellow of the Wallonie-Bruxelles International program and Marie Skłodowska Curie COFUND action. AK is a fellow of the National Science Centre in Poland (UMO2018/30/E/NZ1/00874). RV is funded by an "Aspirant" fellowship (F.R.S.-FNRS) and is a fellow of "Les Amis des Instituts Pasteur à Bruxelles, ASBL." CV is "Directeur de Recherches" at the F.R.S.FNRS. SD, VG, PM, AM, OR, and CV have received funding from the European Union's Horizon 2020 Research and Innovation Program under grant agreement no. 691119-EU4HIVCUREH2020-MSCA-RISE-2015. Work in CV lab was funded by the Belgian Fund for Scientific Research (F.R.S.-FNRS, Belgium), the "Fondation Roi Baudouin," the NEAT program (Networking to Enhance the Use of Economics in Animal Health Education, Research and Policy Making), the Walloon Region (Fonds de Maturation), "Les Amis des Instituts Pasteur à Bruxelles, asbl., and the University of Brussels [Action de Recherche Concertée (ARC) grant]. The laboratory of $\mathrm{CV}$ is part of the ULB-Cancer Research Centre (U-CRC).

Adams, M., Sharmeen, L., Kimpton, J., Romeo, J. M., Garcia, J. V., Peterlin, B. M., et al. (1994). Cellular latency in human immunodeficiency virus-infected individuals with high CD4 levels can be detected by the presence of promoterproximal transcripts. Proc. Natl. Acad. Sci. U.S.A. 91, 3862-3866. doi: 10.1073/ pnas.91.9.3862

Ajamian, L., Abel, K., Rao, S., Vyboh, K., García-de-Gracia, F., Soto-Rifo, R., et al. (2015). HIV-1 recruits UPF1 but excludes UPF2 to promote nucleocytoplasmic export of the genomic RNA. Biomolecules 5, 2808-2839. doi: 10.3390/ biom 5042808

Almodóvar, S., Del, C., Colón, M., Maldonado, I. M., Villafañe, R., Abreu, S., et al. (2007). HIV-1 infection of monocytes is directly related to the success of HAART. Virology 369, 35-46. doi: 10.1016/j.virol.2007.07.010

Archin, N. M., Keedy, K. S., Espeseth, A., Dang, H., Hazuda, D. J., and Margolis, D. M. (2009). Expression of latent human immunodeficiency type 1 is induced 
by novel and selective histone deacetylase inhibitors. AIDS 23, 1799-1806. doi: 10.1097/QAD.0b013e32832ec1dc

Archin, N. M., Liberty, A. L., Kashuba, A. D., Choudhary, S. K., Kuruc, J. D., Crooks, A. M., et al. (2012). Administration of vorinostat disrupts HIV-1 latency in patients on antiretroviral therapy. Nature 487, 482-485. doi: 10.1038/ nature11286

Avettand-Fenoel, V., Hocqueloux, L., Müller-Trutwin, M., Prazuck, T., and Melard, A. (2011). Greater diversity of HIV DNA variants in the rectum compared to variants in the blood in patients without HAART. J. Med. Virol. 83, 1499-1507. doi: $10.1002 / j m v .22132$

Banga, R., Procopio, F. A., Cavassini, M., and Perreau, M. (2016a). In vitro reactivation of replication-competent and infectious HIV-1 by histone deacetylase inhibitors. J. Virol. 90, 1858-1871. doi: 10.1128/JVI.02359-15

Banga, R., Procopio, F. A., Noto, A., Pollakis, G., Cavassini, M., and Ohmiti, K. (2016b). PD-1(+) and follicular helper T cells are responsible for persistent HIV-1 transcription in treated aviremic individuals. Nat. Med. 22, 754-761. doi: $10.1038 / \mathrm{nm} .4113$

Banga, R., Procopio, F. A., Ruggiero, A., Noto, A., Ohmiti, K., Cavassini, M., et al. (2018). Blood CXCR3+ CD4 T cells are enriched in inducible replication competent HIV in aviremic antiretroviral therapy-treated individuals. Front. Immunol. 9:144. doi: 10.3389/fimmu.2018.00144

Bartholomeeusen, K., Xiang, Y., Fujinaga, K., and Peterlin, B. M. (2012). Bromodomain and extra-terminal (BET) bromodomain inhibition activate transcription via transient release of positive transcription elongation factor b (P-TEFb) from 7SK small nuclear ribonucleoprotein. J. Biol. Chem. 287, 36609-36616. doi: 10.1074/jbc.M112.410746

Barton, K., Hiener, B., Winckelmann, A., Rasmussen, T. A., Shao, W., and Byth, K. (2016). Broad activation of latent HIV-1 in vivo. Nat. Commun. 7:12731. doi: 10.1038/ncomms12731

Battivelli, E., Dahabieh, M. S., Abdel-Mohsen, M., Svensson, J. P., Tojal Da Silva, I., and Cohn, L. B. (2018). Distinct chromatin functional states correlate with HIV latency reactivation in infected primary CD4+ T cells. eLife 7:e34655. doi: 10.7554/eLife.34655

Baxter, A. E., Niessl, J., Fromentin, R., Richard, J., Porichis, F., and Charlebois, R. (2016). Single-cell characterization of viral translation-competent reservoirs in HIV-infected individuals. Cell Host Microbe 20, 368-380. doi: 10.1016/j.chom. 2016.07.015

Behrens, N. E., Wertheimer, A., Klotz, S. A., and Ahmad, N. (2018). Reduction in terminally differentiated $\mathrm{T}$ cells in virologically controlled HIV-infected aging patients on long-term antiretroviral therapy. PLoS One 13:e0199101. doi: 10. 1371/journal.pone.0199101

Beliakova-Bethell, N., Hezareh, M., Wong, J. K., Strain, M. C., Lewinski, M. K., and Richman, D. D. (2017). Relative efficacy of T cell stimuli as inducers of productive HIV-1 replication in latently infected CD4 lymphocytes from patients on suppressive cART. Virology 508, 127-133. doi: 10.1016/j.virol.2017. 05.008

Berg, S. L., Stone, J., Xiao, J. J., Chan, K. K., Nuchtern, J., Dauser, R., et al. (2004). Plasma and cerebrospinal fluid pharmacokinetics of depsipeptide (FR901228) in nonhuman primates. Cancer Chemother. Pharmacol. 54, 85-88. doi: 10.1007/ s00280-004-0766-5

Blazkova, J., Murray, D., Justement, J. S., Funk, E. K., Nelson, A. K., and Moir, S. (2012). Paucity of HIV DNA methylation in latently infected, resting CD4+ $\mathrm{T}$ cells from infected individuals receiving antiretroviral therapy. J. Virol. 86, 5390-5392. doi: 10.1128/JVI.00040-12

Blazkova, J., Trejbalova, K., Gondois-Rey, F., Halfon, P., Philibert, P., Guiguen, A., et al. (2009). CpG methylation controls reactivation of HIV from latency. PLoS Pathog. 5:e1000554. doi: 10.1371/journal.ppat.1000554

Boehm, D., Jeng, M., Camus, G., Gramatica, A., Schwarzer, R., Johnson, J. R., et al. (2017). SMYD2-mediated histone methylation contributes to HIV-1 latency. Cell Host Microbe 21, 569-579.e6. doi: 10.1016/j.chom.2017.04.011

Bosque, A., Nilson, K. A., Macedo, A. B., Spivak, A. M., Archin, N. M., Van Wagoner, R. M., et al. (2017). Benzotriazoles reactivate latent HIV-1 through inactivation of STAT5 SUMOylation. Cell Rep. 18, 1324-1334. doi: 10.1016/j. celrep.2017.01.022

Bouchat, S., Delacourt, N., Kula, A., Darcis, G., Van Driessche, B., Corazza, F., et al. (2016). Sequential treatment with 5-aza-2'-deoxycytidine and deacetylase inhibitors reactivates HIV-1. EMBO Mol. Med. 8, 117-138. doi: 10.15252/ emmm. 201505557
Bouchat, S., Gatot, J.-S., Kabeya, K., Cardona, C., Colin, L., Herbein, G., et al. (2012). Histone methyltransferase inhibitors induce HIV-1 recovery in resting CD4(+) T cells from HIV-1-infected HAART-treated patients. AIDS 26, 14731482. doi: 10.1097/QAD.0b013e32835535f5

Bradley, T., Ferrari, G., Haynes, B. F., Margolis, D. M., and Browne, E. P. (2018). Single-cell analysis of quiescent HIV infection reveals host transcriptional profiles that regulate proviral latency. Cell Rep. 25, 107-117.e3. doi: 10.1016/ j.celrep.2018.09.020

Bruner, K. M., Murray, A. J., Pollack, R. A., Soliman, M. G., Laskey, S. B., and Capoferri, A. A. (2016). Defective proviruses rapidly accumulate during acute HIV-1 infection. Nat. Med. 22, 1043-1049. doi: 10.1038/nm.4156

Bruner, K. M., Wang, Z., Simonetti, F. R., Bender, A. M., Kwon, K. J., Sengupta, S., et al. (2019). A quantitative approach for measuring the reservoir of latent HIV-1 proviruses. Nature 566, 120-125. doi: 10.1038/s41586-019-0 898-8

Budhiraja, S., Famiglietti, M., Bosque, A., Planelles, V., and Rice, A. P. (2013). Cyclin T1 and CDK9 T-loop phosphorylation are downregulated during establishment of HIV-1 latency in primary resting memory CD4+ T cells. J. Virol. 87, 1211-1220. doi: 10.1128/JVI.02413-12

Burnett, J. C., Miller-Jensen, K., Shah, P. S., Arkin, A. P., and Schaffer, D. V. (2009). Control of stochastic gene expression by host factors at the HIV promoter. PLoS Pathog. 5:e1000260. doi: 10.1371/journal.ppat.1000260

Buzón, M. J., Codoñer, F. M., Frost, S. D. W., Pou, C., Puertas, M. C., Massanella, M., et al. (2011). Deep molecular characterization of HIV-1 dynamics under suppressive HAART. PLoS Pathog. 7:e1002314. doi: 10.1371/journal.ppat. 1002314

Buzon, M. J., Sun, H., Li, C., Shaw, A., Seiss, K., and Ouyang, Z. (2014). HIV1 persistence in $\mathrm{CD} 4+\mathrm{T}$ cells with stem cell-like properties. Nat. Med. 20, 139-142. doi: 10.1038/nm.3445

Canaud, G., Dejucq-Rainsford, N., Avettand-Fenoël, V., Viard, J.-P., Anglicheau, D., Bienaimé, F., et al. (2014). The kidney as a reservoir for HIV-1 after renal transplantation. J. Am. Soc. Nephrol. 25, 407-419. doi: 10.1681/ASN. 2013050564

Canestri, A., Lescure, F.-X., Jaureguiberry, S., Moulignier, A., Amiel, C., and Marcelin, A. G. (2010). Discordance between cerebral spinal fluid and plasma HIV replication in patients with neurological symptoms who are receiving suppressive antiretroviral therapy. Clin. Infect. Dis. 50, 773-778. doi: 10.1086/ 650538

Cantero-Pérez, J., Grau-Expósito, J., Serra-Peinado, C., Rosero, D. A., LuqueBallesteros, L., Astorga-Gamaza, A., et al. (2019). Resident memory T cells are a cellular reservoir for HIV in the cervical mucosa. Nat. Commun. 10:4739. doi: 10.1038/s41467-019-12732-2

Cao, W., Jamieson, B. D., Hultin, L. E., Hultin, P. M., Effros, R. B., and Detels, R. (2009). Premature aging of T cells is associated with faster HIV-1 disease progression. J. Acquir. Immune Defic. Syndr. 50, 137-147. doi: 10.1097/QAI. 0b013e3181926c28

Caragounis, E.-C., Gisslén, M., Lindh, M., Nordborg, C., Westergren, S., Hagberg, L., et al. (2008). Comparison of HIV-1 pol and env sequences of blood, CSF, brain and spleen isolates collected ante-mortem and post-mortem. Acta Neurol. Scand. 117, 108-116. doi: 10.1111/j.1600-0404.2007.00914.x

Cary, D. C., and Peterlin, B. M. (2018). Procyanidin trimer C1 reactivates latent HIV as a triple combination therapy with kansui and JQ1. PLoS One 13:e0208055. doi: 10.1371/journal.pone.0208055

Casazza, J. P., Betts, M. R., Picker, L. J., and Koup, R. A. (2001). Decay kinetics of human immunodeficiency virus-specific CD8+ T cells in peripheral blood after initiation of highly active antiretroviral therapy. J. Virol. 75, 6508-6516. doi: 10.1128/jvi.75.14.6508-6516.2001

Chang, C. C., Naranbhai, V., Stern, J., Roche, M., Dantanarayana, A., and Ke, R. (2018). Variation in cell-associated unspliced HIV RNA on antiretroviral therapy is associated with the circadian regulator brain-andmuscle-ARNT-like-1. AIDS 32, 2119-2128. doi: 10.1097/QAD.000000000000 1937

Chavez, L., Calvanese, V., and Verdin, E. (2015). HIV latency is established directly and early in both resting and activated primary CD4 T cells. PLoS Pathog. 11:e1004955. doi: 10.1371/journal.ppat.1004955

Chávez, L., Kauder, S., and Verdin, E. (2011). In vivo, in vitro, and in silico analysis of methylation of the HIV-1 provirus. Methods 53, 47-53. doi: 10.1016/j.ymeth. 2010.05.009 
Chen, H.-C., Martinez, J. P., Zorita, E., Meyerhans, A., and Filion, G. J. (2017). Position effects influence HIV latency reversal. Nat. Struct. Mol. Biol. 24, 47-54. doi: $10.1038 / \mathrm{nsmb} .3328$

Chen, H.-C., Zorita, E., and Filion, G. J. (2018). Using barcoded HIV ensembles (B-HIVE) for single provirus transcriptomics. Curr. Protoc. Mol. Biol. 122:e56. doi: $10.1002 /$ cpmb.56

Cherrier, T., Le Douce, V., Eilebrecht, S., Riclet, R., Marban, C., Dequiedt, F., et al. (2013). CTIP2 is a negative regulator of P-TEFb. Proc. Natl. Acad. Sci. U.S.A. 110, 12655-12660. doi: 10.1073/pnas.1220136110

Chomont, N., El-Far, M., Ancuta, P., Trautmann, L., Procopio, F. A., and YassineDiab, B. (2009). HIV reservoir size and persistence are driven by T cell survival and homeostatic proliferation. Nat. Med. 15, 893-900. doi: 10.1038/nm.1972

Chun, T.-W., Carruth, L., Finzi, D., Shen, X., DiGiuseppe, J. A., and Taylor, H. (1997). Quantification of latent tissue reservoirs and total body viral load in HIV-1 infection. Nature 387, 183-188. doi: 10.1038/387183a0

Chun, T.-W., Nickle, D. C., Justement, J. S., Meyers, J. H., Roby, G., Hallahan, C. W., et al. (2008). Persistence of HIV in gut-associated lymphoid tissue despite long-term antiretroviral therapy. J. Infect. Dis. 197, 714-720. doi: 10. $1086 / 527324$

Cicala, C., Martinelli, E., McNally, J. P., Goode, D. J., Gopaul, R., Hiatt, J., et al. (2009). The integrin alpha4beta7 forms a complex with cell-surface CD4 and defines a T-cell subset that is highly susceptible to infection by HIV-1. Proc. Natl. Acad. Sci. U.S.A. 106, 20877-20882. doi: 10.1073/pnas.0911796106

Clutton, G., Xu, Y., Baldoni, P. L., Mollan, K. R., Kirchherr, J., and Newhard, W. (2016). The differential short- and long-term effects of HIV-1 latency-reversing agents on T cell function. Sci. Rep. 6:30749.

Clutton, G. T., and Jones, R. B. (2018). Diverse impacts of HIV latency-reversing agents on CD8+ T-cell function: implications for HIV cure. Front. Immunol. 9:1452. doi: 10.3389/fimmu.2018.01452

Cockerham, L. R., Siliciano, J. D., Sinclair, E., O’Doherty, U., Palmer, S., Yukl, S. A., et al. (2014). CD4+ and CD8+ T cell activation are associated with HIV DNA in resting CD4+ T cells. PLoS One 9:e110731. doi: 10.1371/journal.pone.0110731

Colin, L., and Van Lint, C. (2009). Molecular control of HIV-1 postintegration latency: implications for the development of new therapeutic strategies. Retrovirology 6:111. doi: 10.1186/1742-4690-6-111

Connick, E., Mattila, T., Folkvord, J. M., Schlichtemeier, R., Meditz, A. L., Ray, M. G., et al. (2007). CTL fail to accumulate at sites of HIV-1 replication in lymphoid tissue. J. Immunol. 178, 6975-6983. doi: 10.4049/jimmunol.178.11. 6975

Contreras, X., Barboric, M., Lenasi, T., and Peterlin, B. M. (2007). HMBA releases P-TEFb from HEXIM1 and 7SK snRNA via PI3K/Akt and activates HIV transcription. PLoS Pathog. 3:e146. doi: 10.1371/journal.ppat.0030146

Coombs, R. W., Lockhart, D., Ross, S. O., Deutsch, L., Dragavon, J., Diem, K., et al. (2006). Lower genitourinary tract sources of seminal HIV. J. Acquir. Immune Defic. Syndr. 41, 430-438. doi: 10.1097/01.qai.0000209895.82255.08

Coombs, R. W., Reichelderfer, P. S., and Landay, A. L. (2003). Recent observations on HIV type-1 infection in the genital tract of men and women. AIDS 17, 455-480. doi: 10.1097/00002030-200303070-00001

Core, L. J., and Lis, J. T. (2008). Transcription regulation through promoterproximal pausing of RNA polymerase II. Science 319, 1791-1792. doi: 10.1126/ science. 1150843

Costiniuk, C. T., and Jenabian, M.-A. (2014). The lungs as anatomical reservoirs of HIV infection. Rev. Med. Virol. 24, 35-54. doi: 10.1002/rmv.1772

Couturier, J., Suliburk, J. W., Brown, J. M., Luke, D. J., Agarwal, N., Yu, X., et al. (2015). Human adipose tissue as a reservoir for memory CD4+ T cells and HIV. AIDS 29, 667-674. doi: 10.1097/QAD.0000000000000599

Cribbs, S. K., Lennox, J., Caliendo, A. M., Brown, L. A., and Guidot, D. M. (2015). Healthy HIV-1-infected individuals on highly active antiretroviral therapy harbor HIV-1 in their alveolar macrophages. AIDS Res. Hum. Retroviruses 31, 64-70. doi: 10.1089/AID.2014.0133

Darcis, G., Berkhout, B., and Pasternak, A. O. (2019). The quest for cellular markers of HIV reservoirs: any color you like. Front. Immunol. 10:2251. doi: 10.3389/ fimmu.2019.02251

Darcis, G., Bouchat, S., Kula, A., Van Driessche, B., Delacourt, N., and Vanhulle, C. (2017). Reactivation capacity by latency-reversing agents ex vivo correlates with the size of the HIV-1 reservoir. AIDS 31, 181-189. doi: 10.1097/QAD. 0000000000001290
Darcis, G., Coombs, R. W., and Van Lint, C. (2016). Exploring the anatomical HIV reservoirs: role of the testicular tissue. AIDS 30, 2891-2893. doi: 10.1097/qad. 0000000000001281

Darcis, G., Kula, A., Bouchat, S., Fujinaga, K., Corazza, F., and Ait-Ammar, A. (2015). An in-depth comparison of latency-reversing agent combinations in various in vitro and ex vivo HIV-1 latency models identified bryostatin-1+JQ1 and ingenol-B+JQ1 to potently reactivate viral gene expression. PLoS Pathog. 11:e1005063. doi: 10.1371/journal.ppat.1005063

Das, B., Dobrowolski, C., Luttge, B., Valadkhan, S., Chomont, N., and Johnston, R. (2018). Estrogen receptor-1 is a key regulator of HIV-1 latency that imparts gender-specific restrictions on the latent reservoir. Proc. Natl. Acad. Sci. U.S.A. 115, E7795-E7804. doi: 10.1073/pnas.1803468115

Davey, R. T., Bhat, N., Yoder, C., Chun, T.-W., Metcalf, J. A., and Dewar, R. (1999). HIV-1 and $\mathrm{T}$ cell dynamics after interruption of highly active antiretroviral therapy (HAART) in patients with a history of sustained viral suppression. Proc. Natl. Acad. Sci. U.S.A. 96, 15109-15114. doi: 10.1073/pnas.96.26.15109

De Scheerder, M.-A., Vrancken, B., Dellicour, S., Schlub, T., Lee, E., and Shao, W. (2019). HIV rebound is predominantly fueled by genetically identical viral expansions from diverse reservoirs. Cell Host Microbe 26, 347-358.e7. doi: 10.1016/j.chom.2019.08.003

Debyser, Z., Vansant, G., Bruggemans, A., Janssens, J., and Christ, F. (2018). Insight in HIV integration site selection provides a block-and-lock strategy for a functional cure of HIV infection. Viruses 11:E12. doi: 10.3390/v11010012

DeChristopher, B. A., Loy, B. A., Marsden, M. D., Schrier, A. J., Zack, J. A., and Wender, P. A. (2012). Designed, synthetically accessible bryostatin analogues potently induce activation of latent HIV reservoirs in vitro. Nat. Chem. 4, 705-710. doi: 10.1038/nchem.1395

Deleage, C., Wietgrefe, S. W., Del Prete, G., Morcock, D. R., Hao, X. P., Piatak, M., et al. (2016). Defining HIV and SIV reservoirs in lymphoid tissues. Pathog. Immun. 1, 68-106.

Della Chiara, G., Crotti, A., Liboi, E., Giacca, M., Poli, G., and Lusic, M. (2011). Negative regulation of HIV-1 transcription by a heterodimeric NF- $\kappa$ B1/p50 and C-terminally truncated STAT5 complex. J. Mol. Biol. 410, 933-943. doi: 10.1016/j.jmb.2011.03.044

Delwart, E. L., Mullins, J. I., Gupta, P., Learn, G. H., Holodniy, M., Katzenstein, D., et al. (1998). Human immunodeficiency virus type 1 populations in blood and semen. J. Virol. 72, 617-623. doi: 10.1128/jvi.72.1.617-623.1998

Deng, K., Pertea, M., Rongvaux, A., Wang, L., Durand, C. M., Ghiaur, G., et al. (2015). Broad CTL response is required to clear latent HIV-1 due to dominance of escape mutations. Nature 517, 381-385. doi: 10.1038/nature14053

Descours, B., Petitjean, G., López-Zaragoza, J.-L., Bruel, T., Raffel, R., Psomas, C., et al. (2017). CD32a is a marker of a CD4 T-cell HIV reservoir harbouring replication-competent proviruses. Nature 543, 564-567. doi: 10. 1038 /nature21710

Desimio, M. G., Giuliani, E., and Doria, M. (2017). The histone deacetylase inhibitor SAHA simultaneously reactivates HIV-1 from latency and upregulates NKG2D ligands sensitizing for natural killer cell cytotoxicity. Virology 510, 9-21. doi: 10.1016/j.virol.2017.06.033

Desimio, M. G., Giuliani, E., Ferraro, A. S., Adorno, G., and Doria, M. (2018). In vitro exposure to prostratin but not bryostatin-1 improves natural killer cell functions including killing of CD4+ T cells harboring reactivated human immunodeficiency virus. Front. Immunol. 9:1514. doi: 10.3389/fimmu.2018. 01514

Diem, K., Nickle, D. C., Motoshige, A., Fox, A., Ross, S., Mullins, J. I., et al. (2008). Male genital tract compartmentalization of human immunodeficiency virus type 1 (HIV). AIDS Res. Hum. Retroviruses 24, 561-571. doi: 10.1089/aid.2007. 0115

Ding, D., Qu, X., Li, L., Zhou, X., Liu, S., Lin, S., et al. (2013). Involvement of histone methyltransferase GLP in HIV-1 latency through catalysis of H3K9 dimethylation. Virology 440, 182-189. doi: 10.1016/j.virol.2013.02.022

Doyon, G., Zerbato, J., Mellors, J. W., and Sluis-Cremer, N. (2013). Disulfiram reactivates latent HIV-1 expression through depletion of the phosphatase and tensin homolog. AIDS 27, F7-F11. doi: 10.1097/QAD.0b013e3283570620

du Chéné, I., Basyuk, E., Lin, Y.-L., Triboulet, R., Knezevich, A., and Chable-Bessia, C. (2007). Suv39H1 and HP1gamma are responsible for chromatin-mediated HIV-1 transcriptional silencing and post-integration latency. EMBO J. 26, 424-435. doi: 10.1038/sj.emboj.7601517 
Eilebrecht, S., Le Douce, V., Riclet, R., Targat, B., Hallay, H., Van Driessche, B., et al. (2014). HMGA1 recruits CTIP2-repressed P-TEFb to the HIV-1 and cellular target promoters. Nucleic Acids Res. 42, 4962-4971. doi: 10.1093/nar/gk u168

Einkauf, K. B., Lee, G. Q., Gao, C., Sharaf, R., Sun, X., and Hua, S. (2019). Intact HIV-1 proviruses accumulate at distinct chromosomal positions during prolonged antiretroviral therapy. J. Clin. Invest. 129, 988-998. doi: 10.1172/ JCI124291

Eisele, E., and Siliciano, R. F. (2012). Redefining the viral reservoirs that prevent HIV-1 eradication. Immunity 37, 377-388. doi: 10.1016/j.immuni.2012.08.010

Elliott, J. H., McMahon, J. H., Chang, C. C., Lee, S. A., Hartogensis, W., and Bumpus, N. (2015). Short-term administration of disulfiram for reversal of latent HIV infection: a phase 2 dose-escalation study. Lancet HIV 2, e520-e529. doi: 10.1016/S2352-3018(15)00226-X

Elliott, J. H., Wightman, F., Solomon, A., Ghneim, K., Ahlers, J., and Cameron, M. J. (2014). Activation of HIV transcription with short-course vorinostat in HIV-infected patients on suppressive antiretroviral therapy. PLoS Pathog. 10:e1004473. doi: 10.1371/journal.ppat.1004473

Evans, V. A., van der Sluis, R. M., Solomon, A., Dantanarayana, A., McNeil, C., Garsia, R., et al. (2018). Programmed cell death-1 contributes to the establishment and maintenance of HIV-1 latency. AIDS 32, 1491-1497. doi: 10.1097/QAD.0000000000001849

Evering, T. H., Mehandru, S., Racz, P., Tenner-Racz, K., Poles, M. A., Figueroa, A., et al. (2012). Absence of HIV-1 evolution in the gut-associated lymphoid tissue from patients on combination antiviral therapy initiated during primary infection. PLoS Pathog. 8:e1002506. doi: 10.1371/journal.ppat.1002506

Fletcher, C. V., Staskus, K., Wietgrefe, S. W., Rothenberger, M., Reilly, C., Chipman, J. G., et al. (2014). Persistent HIV-1 replication is associated with lower antiretroviral drug concentrations in lymphatic tissues. Proc. Natl. Acad. Sci. U.S.A. 111, 2307-2312. doi: 10.1073/pnas.1318249111

Forlani, G., Tosi, G., Turrini, F., Poli, G., Vicenzi, E., and Accolla, R. S. (2017). Tripartite motif-containing protein 22 interacts with class II transactivator and orchestrates its recruitment in nuclear bodies containing TRIM19/PML and cyclin T1. Front. Immunol. 8:564. doi: 10.3389/fimmu.2017.00564

Forouzanfar, F., Ali, S., Wallet, C., Rovere, M. D., Ducloy, C., Mekdad, H. E., et al. (2019). HIV-1 Vpr mediates the depletion of the cellular repressor CTIP2 to counteract viral gene silencing. Sci. Rep. 9:13154. doi: 10.1038/s41598-01948689-x

Friedman, J., Cho, W.-K., Chu, C. K., Keedy, K. S., Archin, N. M., Margolis, D. M., et al. (2011). Epigenetic silencing of HIV-1 by the histone H3 lysine 27 methyltransferase enhancer of zeste $2 \nabla$. J. Virol. 85 , 9078-9089. doi: 10.1128/ JVI.00836-11

Fromentin, R., Bakeman, W., Lawani, M. B., Khoury, G., Hartogensis, W., DaFonseca, S., et al. (2016). CD4+ T cells expressing PD-1, TIGIT and LAG3 contribute to HIV persistence during ART. PLoS Pathog. 12:e1005761. doi: 10.1371/journal.ppat.1005761

Ganor, Y., Real, F., Sennepin, A., Dutertre, C.-A., Prevedel, L., Xu, L., et al. (2019). HIV-1 reservoirs in urethral macrophages of patients under suppressive antiretroviral therapy. Nat. Microbiol. 4, 633-644. doi: 10.1038/s41564-0180335-z

Garrido, C., Spivak, A. M., Soriano-Sarabia, N., Checkley, M. A., Barker, E., Karn, J., et al. (2016). HIV latency-reversing agents have diverse effects on natural killer cell function. Front. Immunol. 7:356. doi: 10.3389/fimmu.2016.00356

Gattinoni, L., Lugli, E., Ji, Y., Pos, Z., Paulos, C. M., and Quigley, M. F. (2011). A human memory $\mathrm{T}$ cell subset with stem cell-like properties. Nat. Med. 17, 1290-1297. doi: 10.1038/nm.2446

Geng, G., Liu, B., Chen, C., Wu, K., Liu, J., and Zhang, Y. (2016). Development of an attenuated tat protein as a highly-effective agent to specifically activate HIV-1 latency. Mol. Ther. 24, 1528-1537. doi: 10.1038/mt.2016.117

Gianella, S., Kosakovsky Pond, S. L., Oliveira, M. F., Scheffler, K., Strain, M. C., and De la Torre, A. (2016). Compartmentalized HIV rebound in the central nervous system after interruption of antiretroviral therapy. Virus Evol. 2:vew020. doi: $10.1093 /$ ve/vew020

Gibellini, D., Borderi, M., De Crignis, E., Cicola, R., Cimatti, L., Vitone, F., et al. (2008). HIV-1 DNA load analysis in peripheral blood lymphocytes and monocytes from naïve and HAART-treated individuals. J. Infect. 56, 219-225. doi: 10.1016/j.jinf.2008.01.001
Gohda, J., Suzuki, K., Liu, K., Xie, X., Takeuchi, H., Inoue, J.-I., et al. (2018). BI2536 and BI-6727, dual Polo-like kinase/bromodomain inhibitors, effectively reactivate latent HIV-1. Sci. Rep. 8:3521. doi: 10.1038/s41598-018-21942-5

Golumbeanu, M., Cristinelli, S., Rato, S., Munoz, M., Cavassini, M., Beerenwinkel, N., et al. (2018). Single-cell RNA-seq reveals transcriptional heterogeneity in latent and reactivated HIV-infected cells. Cell Rep. 23, 942-950. doi: 10.1016/j. celrep.2018.03.102

Gosselin, A., Monteiro, P., Chomont, N., Diaz-Griffero, F., Said, E. A., Fonseca, S., et al. (2010). Peripheral blood CCR4+CCR6+ and CXCR3+CCR6+CD4+ $\mathrm{T}$ cells are highly permissive to HIV-1 infection. J. Immunol. 184, 1604-1616. doi: 10.4049/jimmunol.0903058

Gosselin, A., Wiche Salinas, T. R., Planas, D., Wacleche, V. S., Zhang, Y., and Fromentin, R. (2017). HIV persists in CCR6+CD4+ T cells from colon and blood during antiretroviral therapy. AIDS 31, 35-48. doi: 10.1097/qad. 0000000000001309

Gras, G., and Kaul, M. (2010). Molecular mechanisms of neuroinvasion by monocytes-macrophages in HIV-1 infection. Retrovirology 7:30. doi: 10.1186/ 1742-4690-7-30

Grau-Expósito, J., Luque-Ballesteros, L., Navarro, J., Curran, A., Burgos, J., and Ribera, E. (2019). Latency reversal agents affect differently the latent reservoir present in distinct CD4+ T subpopulations. PLoS Pathog. 15:e1007991. doi: 10.1371/journal.ppat.1007991

Gray, C. M., Lawrence, J., Schapiro, J. M., Altman, J. D., and Winters, M. A. (1999). Frequency of class I HLA-restricted anti-HIV CD8+ T cells in individuals receiving highly active antiretroviral therapy (HAART). J. Immunol. 162, 17801788 .

Greger, I. H., Demarchi, F., Giacca, M., and Proudfoot, N. J. (1998). Transcriptional interference perturbs the binding of Sp1 to the HIV-1 promoter. Nucleic Acids Res. 26, 1294-1301. doi: 10.1093/nar/26.5.1294

Guihot, A., Marcelin, A.-G., Massiani, M.-A., Samri, A., Soulié, C., Autran, B., et al. (2018). Drastic decrease of the HIV reservoir in a patient treated with nivolumab for lung cancer. Ann. Oncol. 29, 517-518. doi: 10.1093/annonc/ mdx696

Gunst, J. D., Kjær, K., Olesen, R., Rasmussen, T. A., Østergaard, L., Denton, P. W., et al. (2019). Fimepinostat, a novel dual inhibitor of HDAC and PI3K, effectively reverses HIV-1 latency ex vivo without T cell activation. J. Virus Erad. $5,133-137$.

Hakre, S., Chavez, L., Shirakawa, K., and Verdin, E. (2012). HIV latency: experimental systems and molecular models. FEMS Microbiol. Rev. 36, 706-716. doi: 10.1111/j.1574-6976.2012.00335.x

Han, Y., Lassen, K., Monie, D., Sedaghat, A. R., Shimoji, S., Liu, X., et al. (2004). Resting CD4+ T cells from human immunodeficiency virus type 1 (HIV-1)infected individuals carry integrated HIV-1 genomes within actively transcribed host genes. J. Virol. 78, 6122-6133. doi: 10.1128/jvi.78.12.6122-6133.2004

Han, Y., Lin, Y. B., An, W., Xu, J., Yang, H.-C., O'Connell, K., et al. (2008). Orientation-dependent regulation of integrated HIV-1 expression by host gene transcriptional readthrough. Cell Host Microbe 4, 134-146. doi: 10.1016/j.chom. 2008.06.008

Hattori, S., Matsuda, K., Tsuchiya, K., Gatanaga, H., Oka, S., and Yoshimura, K. (2018). Combination of a latency-reversing agent with a Smac mimetic minimizes secondary HIV-1 infection in vitro. Front. Microbiol. 9:2022. doi: 10.3389/fmicb.2018.02022

Hayashi, T., Jean, M., Huang, H., Simpson, S., Santoso, N. G., and Zhu, J. (2017). Screening of an FDA-approved compound library identifies levosimendan as a novel anti-HIV-1 agent that inhibits viral transcription. Antiviral Res. 146, 76-85. doi: 10.1016/j.antiviral.2017.08.013

Heesters, B. A., Lindqvist, M., Vagefi, P. A., Scully, E. P., Schildberg, F. A., and Altfeld, M. (2015). Follicular dendritic cells retain infectious HIV in cycling endosomes. PLoS Pathog. 11:e1005285. doi: 10.1371/journal.ppat.1005285

Hiener, B., Horsburgh, B. A., Eden, J.-S., Barton, K., Schlub, T. E., and Lee, E. (2017). Identification of genetically intact HIV-1 proviruses in specific CD4+ $\mathrm{T}$ cells from effectively treated participants. Cell Rep. 21, 813-822. doi: 10.1016/ j.celrep.2017.09.081

Ho, Y.-C., Shan, L., Hosmane, N. N., Wang, J., Laskey, S. B., Rosenbloom, D. I. S., et al. (2013). Replication-competent noninduced proviruses in the latent reservoir increase barrier to HIV-1 cure. Cell 155, 540-551. doi: 10.1016/j.cell. 2013.09.020 
Hogan, L. E., Vasquez, J., Hobbs, K. S., Hanhauser, E., Aguilar-Rodriguez, B., and Hussien, R. (2018). Increased HIV-1 transcriptional activity and infectious burden in peripheral blood and gut-associated CD4+ T cells expressing CD30. PLoS Pathog. 14:e1006856. doi: 10.1371/journal.ppat.1006856

Honeycutt, J. B., Thayer, W. O., Baker, C. E., Ribeiro, R. M., Lada, S. M., Cao, Y., et al. (2017). HIV persistence in tissue macrophages of humanized myeloidonly mice during antiretroviral therapy. Nat. Med. 23, 638-643. doi: 10.1038/ nm.4319

Houzet, L., Pérez-Losada, M., Matusali, G., Deleage, C., Dereuddre-Bosquet, N., Satie, A.-P., et al. (2018). Seminal simian immunodeficiency virus in chronically infected cynomolgus macaques is dominated by virus originating from multiple genital organs. J. Virol. 92:e00133-18. doi: 10.1128/JVI.00133-18

$\mathrm{Hu}, \mathrm{Z}$., and Kuritzkes, D. R. (2014). Altered viral fitness and drug susceptibility in HIV-1 carrying mutations that confer resistance to nonnucleoside reverse transcriptase and integrase strand transfer inhibitors. J. Virol. 88, 9268-9276. doi: 10.1128/JVI.00695-14

Huang, H., Kong, W., Jean, M., Fiches, G., Zhou, D., Hayashi, T., et al. (2019). A CRISPR/Cas9 screen identifies the histone demethylase MINA53 as a novel HIV-1 latency-promoting gene (LPG). Nucleic Acids Res. 47, 7333-7347. doi: 10.1093/nar/gkz493

Huang, H., Liu, S., Jean, M., Simpson, S., Huang, H., and Merkley, M. (2017). A novel bromodomain inhibitor reverses HIV-1 latency through specific binding with BRD4 to promote tat and P-TEFb association. Front. Microbiol. 8:1035. doi: 10.3389/fmicb.2017.01035

Huang, J., Wang, F., Argyris, E., Chen, K., Liang, Z., and Tian, H. (2007). Cellular microRNAs contribute to HIV-1 latency in resting primary CD4+ T lymphocytes. Nat. Med. 13, 1241-1247. doi: 10.1038/nm1639

Hurst, J., Hoffmann, M., Pace, M., Williams, J. P., Thornhill, J., Hamlyn, E., et al. (2015). Immunological biomarkers predict HIV-1 viral rebound after treatment interruption. Nat. Commun. 6:8495. doi: 10.1038/ncomms 9495

Iglesias-Ussel, M., Vandergeeten, C., Marchionni, L., Chomont, N., and Romerio, F. (2013). High levels of CD2 expression identify HIV-1 latently infected resting memory CD4+ T cells in virally suppressed subjects. J. Virol. 87, 9148-9158. doi: 10.1128/JVI.01297-13

Imai, K., Togami, H., and Okamoto, T. (2010). Involvement of histone H3 lysine 9 (H3K9) methyltransferase G9a in the maintenance of HIV-1 latency and its reactivation by BIX01294. J. Biol. Chem. 285, 16538-16545. doi: 10.1074/jbc. M110.103531

Imamichi, H., Degray, G., Dewar, R. L., Mannon, P., Yao, M., Chairez, C., et al. (2011). Lack of compartmentalization of HIV-1 quasispecies between the gut and peripheral blood compartments. J. Infect. Dis. 204, 309-314. doi: 10.1093/ infdis/jir259

Iversen, A. K. N., Attermann, J., Gerstoft, J., Fugger, L., Mullins, J. I., and Skinhøj, P. (2004). Longitudinal and cross-sectional studies of HIV-1 RNA and DNA loads in blood and the female genital tract. Eur. J. Obstet. Gynecol. Reprod. Biol. 117, 227-235. doi: 10.1016/j.ejogrb.2004.05.016

Jadlowsky, J. K., Wong, J. Y., Graham, A. C., Dobrowolski, C., Devor, R. L., Adams, M. D., et al. (2014). Negative elongation factor is required for the maintenance of proviral latency but does not induce promoter-proximal pausing of RNA polymerase II on the HIV long terminal repeat. Mol. Cell Biol. 34, 1911-1928. doi: 10.1128/MCB.01013-13

Jean, M. J., Hayashi, T., Huang, H., Brennan, J., Simpson, S., and Purmal, A. (2017). Curaxin CBL0100 blocks HIV-1 replication and reactivation through inhibition of viral transcriptional elongation. Front. Microbiol. 8:2007. doi: 10.3389/fmicb. 2017.02007

Jenabian, M.-A., Costiniuk, C. T., Mehraj, V., Ghazawi, F. M., Fromentin, R., Brousseau, J., et al. (2016). Immune tolerance properties of the testicular tissue as a viral sanctuary site in ART-treated HIV-infected adults. AIDS 30, 2777-2786. doi: 10.1097/qad.0000000000001282

Jiang, G., Espeseth, A., Hazuda, D. J., and Margolis, D. M. (2007). c-Myc and $\mathrm{Sp} 1$ contribute to proviral latency by recruiting histone deacetylase 1 to the human immunodeficiency virus type 1 promoter. J. Virol. 81, 10914-10923. doi: $10.1128 /$ jvi.01208-07

Jiang, G., Mendes, E. A., Kaiser, P., Sankaran-Walters, S., Tang, Y., and Weber, M. G. (2014). Reactivation of HIV latency by a newly modified Ingenol derivative via protein kinase $\mathrm{C} \delta-\mathrm{NF}-\kappa \mathrm{B}$ signaling. AIDS 28, 1555-1566. doi: $10.1097 /$ qad.0000000000000289
Jiang, G., Mendes, E. A., Kaiser, P., Wong, D. P., Tang, Y., Cai, I., et al. (2015). Synergistic reactivation of latent HIV expression by Ingenol-3angelate, PEP005, targeted NF-kB signaling in combination with JQ1 induced p-TEFb activation. PLoS Pathog. 11:e1005066. doi: 10.1371/journal.ppat.100 5066

Jiang, G., Nguyen, D., Archin, N. M., Yukl, S. A., Méndez-Lagares, G., Tang, Y., et al. (2018). HIV latency is reversed by ACSS2-driven histone crotonylation. J. Clin. Invest. 128, 1190-1198. doi: 10.1172/JCI98071

Jones, R. B., Mueller, S., O’Connor, R., Rimpel, K., Sloan, D. D., and Karel, D. (2016). A subset of latency-reversing agents expose HIV-infected resting CD4+ T-cells to recognition by cytotoxic T-lymphocytes. PLoS Pathog. 12:e1005545. doi: 10.1371/journal.ppat.1005545

Jones, R. B., O’Connor, R., Mueller, S., Foley, M., Szeto, G. L., and Karel, D. (2014). Histone deacetylase inhibitors impair the elimination of HIV-infected cells by cytotoxic T-lymphocytes. PLoS Pathog. 10:e1004287. doi: 10.1371/journal.ppat. 1004287

Kaiser, P., Joshi, S. K., Kim, P., Li, P., Liu, H., and Rice, A. P. (2017). Assays for precise quantification of total (including short) and elongated HIV-1 transcripts. J. Virol. Methods 242, 1-8. doi: 10.1016/j.jviromet.2016.12.017

Kandathil, A. J., Sugawara, S., and Balagopal, A. (2016). Are T cells the only HIV-1 reservoir? Retrovirology 13:86.

Kauder, S. E., Bosque, A., Lindqvist, A., Planelles, V., and Verdin, E. (2009). Epigenetic regulation of HIV-1 latency by cytosine methylation. PLoS Pathog. 5:e1000495. doi: 10.1371/journal.ppat.1000495

Kessing, C. F., Nixon, C. C., Li, C., Tsai, P., Takata, H., and Mousseau, G. (2017). In vivo suppression of HIV rebound by didehydro-cortistatin A, a 'block-andlock' strategy for HIV-1 treatment. Cell Rep. 21, 600-611. doi: 10.1016/j.celrep. 2017.09.080

Kim, Y., Anderson, J. L., and Lewin, S. R. (2018). Getting the "kill" into "shock and kill": strategies to eliminate latent HIV. Cell Host Microbe 23, 14-26. doi: 10.1016/j.chom.2017.12.004

Klase, Z., Kale, P., Winograd, R., Gupta, M. V., Heydarian, M., Berro, R., et al. (2007). HIV-1 TAR element is processed by Dicer to yield a viral micro-RNA involved in chromatin remodeling of the viral LTR. BMC Mol. Biol. 8:63. doi: 10.1186/1471-2199-8-63

Klein, K., Nickel, G., Nankya, I., Kyeyune, F., Demers, K., Ndashimye, E., et al. (2018). Higher sequence diversity in the vaginal tract than in blood at early HIV-1 infection. PLoS Pathog. 14:e1006754. doi: 10.1371/journal.ppat.1006754

Kohler, S. L., Pham, M. N., Folkvord, J. M., Arends, T., Miller, S. M., Miles, B., et al. (2016). Germinal center T follicular helper cells are highly permissive to HIV-1 and alter their phenotype during virus replication. J. Immunol. 196, 2711-2722. doi: 10.4049/jimmunol.1502174

Kuai, Q., Lu, X., Qiao, Z., Wang, R., Wang, Y., and Ye, S. (2018). Histone deacetylase inhibitor chidamide promotes reactivation of latent human immunodeficiency virus by introducing histone acetylation. J. Med. Virol. 90, 1478-1485. doi: 10.1002/jmv.25207

Kula, A., Delacourt, N., Bouchat, S., Darcis, G., Avettand-Fenoel, V., and Verdikt, R. (2019). Heterogeneous HIV-1 reactivation patterns of disulfiram and combined disulfiram+romidepsin treatments. J. Acquir. Immune Defic. Syndr. 80, 605-613. doi: 10.1097/QAI.0000000000001958

Kula, A., Gharu, L., and Marcello, A. (2013). HIV-1 pre-mRNA commitment to Rev mediated export through PSF and matrin 3. Virology 435, 329-340. doi: 10.1016/j.virol.2012.10.032

Kula, A., Guerra, J., Knezevich, A., Kleva, D., Myers, M. P., and Marcello, A. (2011). Characterization of the HIV-1 RNA associated proteome identifies matrin 3 as a nuclear cofactor of Rev function. Retrovirology 8:60. doi: 10.1186/1742-46908-60

Kulkosky, J., Culnan, D. M., Roman, J., Dornadula, G., Schnell, M., Boyd, M. R., et al. (2001). Prostratin: activation of latent HIV-1 expression suggests a potential inductive adjuvant therapy for HAART. Blood 98, 3006-3015. doi: 10.1182/blood.v98.10.3006

Kulpa, D. A., Talla, A., Brehm, J. H., Ribeiro, S. P., Yuan, S., and Bebin-Blackwell, A.-G. (2019). Differentiation into an effector memory phenotype potentiates HIV-l latency reversal in CD4+ T cells. J. Virol. 93:e00969-19. doi: 10.1128/JVI. 00969-19

Kumar, A., Abbas, W., and Herbein, G. (2014). HIV-1 latency in monocytes/macrophages. Viruses 6, 1837-1860. doi: 10.3390/v6041837 
Laird, G. M., Bullen, C. K., Rosenbloom, D. I. S., Martin, A. R., Hill, A. L., Durand, C. M., et al. (2015). Ex vivo analysis identifies effective HIV-1 latency-reversing drug combinations. J. Clin. Invest. 125, 1901-1912. doi: 10.1172/JCI80142

Lambotte, O., Taoufik, Y., de Goër, M. G., Wallon, C., Goujard, C., and Delfraissy, J. F. (2000). Detection of infectious HIV in circulating monocytes from patients on prolonged highly active antiretroviral therapy. J. Acquir. Immune Defic. Syndr. 23, 114-119. doi: 10.1097/00126334-200002010-00002

Lassen, K. G., Ramyar, K. X., Bailey, J. R., Zhou, Y., and Siliciano, R. F. (2006). Nuclear retention of multiply spliced HIV-1 RNA in resting CD4+ T cells. PLoS Pathog. 2:e68. doi: 10.1371/journal.ppat.0020068

Lavolé, A., Guihot, A., Veyri, M., Lambotte, O., Autran, B., Cloarec, N., et al. (2018). PD-1 blockade in HIV-infected patients with lung cancer: a new challenge or already a strategy? Ann. Oncol. 29, 1065-1066. doi: 10.1093/annonc/md x 817

Le Garff, G., Samri, A., Lambert-Niclot, S., Even, S., Lavolé, A., and Cadranel, J. (2017). Transient HIV-specific T cells increase and inflammation in an HIVinfected patient treated with nivolumab. AIDS 31, 1048-1051. doi: 10.1097/ qad.0000000000001429

Lenasi, T., Contreras, X., and Peterlin, B. M. (2008). Transcriptional interference antagonizes proviral gene expression to promote HIV latency. Cell Host Microbe 4, 123-133. doi: 10.1016/j.chom.2008.05.016

Lerner, P., Guadalupe, M., Donovan, R., Hung, J., Flamm, J., Prindiville, T., et al. (2011). The gut mucosal viral reservoir in HIV-infected patients is not the major source of rebound plasma viremia following interruption of highly active antiretroviral therapy. J. Virol. 85, 4772-4782. doi: 10.1128/jvi.02409-10

Leth, S., Schleimann, M. H., Nissen, S. K., Højen, J. F., Olesen, R., and Graversen, M. E. (2016). Combined effect of Vacc-4x, recombinant human granulocyte macrophage colony-stimulating factor vaccination, and romidepsin on the HIV-1 reservoir (REDUC): a single-arm, phase $1 \mathrm{~B} / 2 \mathrm{~A}$ trial. Lancet $H I V$, e463-e472. doi: 10.1016/S2352-3018(16)30055-8

Lewis, M. J., Frohnen, P., Ibarrondo, F. J., Reed, D., Iyer, V., Ng, H. L., et al. (2013). HIV-1 Nef sequence and functional compartmentalization in the gut is not due to differential cytotoxic T lymphocyte selective pressure. PLoS One 8:e75620. doi: 10.1371/journal.pone.0075620

Li, H., and Pauza, C. D. (2011). HIV envelope-mediated, CCR5/ $\alpha 4 \beta 7$-dependent killing of CD4-negative $\gamma \delta \mathrm{T}$ cells which are lost during progression to AIDS. Blood 118, 5824-5831. doi: 10.1182/blood-2011-05-356535

Li, J., Chen, C., Ma, X., Geng, G., Liu, B., Zhang, Y., et al. (2016). Long noncoding RNA NRON contributes to HIV-1 latency by specifically inducing tat protein degradation. Nat. Commun. 7:11730. doi: 10.1038/ncomms11730

Li, Z., Mbonye, U., Feng, Z., Wang, X., Gao, X., Karn, J., et al. (2018). The KAT5-acetyl-histone4-Brd4 axis silences HIV-1 transcription and promotes viral latency. PLoS Pathog. 14:e1007012. doi: 10.1371/journal.ppat.1007012

Liang, T., Zhang, X., Lai, F., Lin, J., Zhou, C., and Xu, X. (2019). A novel bromodomain inhibitor, CPI-203, serves as an HIV-1 latency-reversing agent by activating positive transcription elongation factor b. Biochem. Pharmacol. 164, 237-251. doi: 10.1016/j.bcp.2019.04.005

López-Huertas, M. R., Jiménez-Tormo, L., Madrid-Elena, N., Gutiérrez, C., Rodríguez-Mora, S., and Coiras, M. (2017). The CCR5-antagonist maraviroc reverses HIV-1 latency in vitro alone or in combination with the PKC-agonist bryostatin-1. Sci. Rep. 7:2385. doi: 10.1038/s41598-017-02634-y

Lu, P., Qu, X., Shen, Y., Jiang, Z., Wang, P., and Zeng, H. (2016). The BET inhibitor OTX015 reactivates latent HIV-1 through P-TEFb. Sci. Rep. 6:24100. doi: 10.1038/srep24100

Lu, P., Shen, Y., Yang, H., Wang, Y., Jiang, Z., Yang, X., et al. (2017). BET inhibitors RVX-208 and PFI-1 reactivate HIV-1 from latency. Sci. Rep. 7:16646. doi: 10.1038/s41598-017-16816-1

Lusic, M., Marcello, A., Cereseto, A., and Giacca, M. (2003). Regulation of HIV1 gene expression by histone acetylation and factor recruitment at the LTR promoter. EMBO J. 22, 6550-6561. doi: 10.1093/emboj/cdg631

Madrid-Elena, N., García-Bermejo, M. L., Serrano-Villar, S., Díaz-de Santiago, A., Sastre, B., and Gutiérrez, C. (2018). Maraviroc is associated with latent $\mathrm{HIV}-1$ reactivation through $\mathrm{NF}-\kappa \mathrm{B}$ activation in resting CD4+ $\mathrm{T}$ cells from $\mathrm{HIV}$-infected individuals on suppressive antiretroviral therapy. J. Virol. 92:e019 31-17.

Malim, M. H., and Cullen, B. R. (1991). HIV-1 structural gene expression requires the binding of multiple Rev monomers to the viral RRE: implications for HIV-1 latency. Cell 65, 241-248. doi: 10.1016/0092-8674(91)90158-u
Marban, C., Suzanne, S., Dequiedt, F., de Walque, S., Redel, L., Van Lint, C., et al. (2007). Recruitment of chromatin-modifying enzymes by CTIP2 promotes HIV-1 transcriptional silencing. EMBO J. 26, 412-423. doi: 10.1038/sj.emboj. 7601516

Marcelin, A.-G., Tubiana, R., Lambert-Niclot, S., Lefebvre, G., Dominguez, S., Bonmarchand, M., et al. (2008). Detection of HIV-1 RNA in seminal plasma samples from treated patients with undetectable HIV-1 RNA in blood plasma. AIDS 22, 1677-1679. doi: 10.1097/QAD.0b013e32830abdc8

Marini, B., Kertesz-Farkas, A., Ali, H., Lucic, B., Lisek, K., Manganaro, L., et al. (2015). Nuclear architecture dictates HIV-1 integration site selection. Nature 521, 227-231. doi: 10.1038/nature14226

Martin, G. E., Pace, M., Thornhill, J. P., Phetsouphanh, C., Meyerowitz, J., Gossez, M., et al. (2018). CD32-expressing CD4 T cells are phenotypically diverse and can contain proviral HIV DNA. Front. Immunol. 9:928. doi: 10.3389/fimmu. 2018.00928

Massanella, M., Bakeman, W., Sithinamsuwan, P., Fletcher, J. L. K., Chomchey, N., Tipsuk, S., et al. (2019). Infrequent HIV infection of circulating monocytes during antiretroviral therapy. J. Virol. 94:e01174-19. doi: 10.1128/JVI.01174-19

Mates, J. M., de Silva, S., Lustberg, M., Van Deusen, K., Baiocchi, R. A., Wu, L., et al. (2015). A novel histone deacetylase inhibitor, AR-42, reactivates HIV-1 from chronically and latently infected CD4+ T-cells. Retrovirology 7, 1-5.

McGary, C. S., Deleage, C., Harper, J., Micci, L., Ribeiro, S. P., Paganini, S., et al. (2017). CTLA-4+PD-1- memory CD4+ T cells critically contribute to viral persistence in antiretroviral therapy-suppressed, SIV-infected rhesus macaques. Immunity 47, 776-788.e5. doi: 10.1016/j.immuni.2017.09.018

McNamara, L. A., Onafuwa-Nuga, A., Sebastian, N. T., Riddell, J., Bixby, D., and Collins, K. L. (2013). CD133+ hematopoietic progenitor cells harbor HIV genomes in a subset of optimally treated people with long-term viral suppression. J. Infect. Dis. 207, 1807-1816. doi: 10.1093/infdis/jit118

Miller, R. L., Ponte, R., Jones, B. R., Kinloch, N. N., Omondi, F. H., and Jenabian, M.-A. (2019). HIV diversity and genetic compartmentalization in blood and testes during suppressive antiretroviral therapy. J. Virol. 93:e00755-19. doi: 10.1128/JVI.00755-19

Miyawaki, T., Kasahara, Y., Taga, K., Yachie, A., and Taniguchi, N. (1990). Differential expression of CD45RO (UCHL1) and its functional relevance in two subpopulations of circulating TCR-gamma/delta+ lymphocytes. J. Exp. Med. 171, 1833-1838. doi: 10.1084/jem.171.5.1833

Modai, S., Farberov, L., Herzig, E., Isakov, O., Hizi, A., and Shomron, N. (2019). HIV-1 infection increases microRNAs that inhibit Dicer1, HRB and HIV-EP2, thereby reducing viral replication. PLoS One 14:e0211111. doi: 10.1371/journal. pone.0211111

Mohammadi, P., di Iulio, J., Muñoz, M., Martinez, R., Bartha, I., and Cavassini, M. (2014). Dynamics of HIV latency and reactivation in a primary CD4+ T cell model. PLoS Pathog. 10:e1004156. doi: 10.1371/journal.ppat.1004156

Moron-Lopez, S., Kim, P., Søgaard, O. S., Tolstrup, M., Wong, J. K., and Yukl, S. A. (2019). Characterization of the HIV-1 transcription profile after romidepsin administration in ART-suppressed individuals. AIDS 33, 425-431. doi: 10.1097/ QAD.0000000000002083

Mousseau, G., Aneja, R., Clementz, M. A., Mediouni, S., Lima, N. S., Haregot, A., et al. (2019). Resistance to the tat inhibitor didehydro-cortistatin a is mediated by heightened basal HIV-1 transcription. mBio 10:e1750-18. doi: 10.1128/ mBio.01750-18

Nguyen, K., Das, B., Dobrowolski, C., and Karn, J. (2017). Multiple histone lysine methyltransferases are required for the establishment and maintenance of HIV-1 latency. mBio 8:e0133-17. doi: 10.1128/mBio.00133-17

Nguyen, V. T., Kiss, T., Michels, A. A., and Bensaude, O. (2001). 7SK small nuclear RNA binds to and inhibits the activity of CDK9/cyclin T complexes. Nature 414, 322-325. doi: 10.1038/35104581

Nolan, D. J., Rose, R., Rodriguez, P. H., Salemi, M., Singer, E. J., and Lamers, S. L. (2018). The spleen is an HIV-1 sanctuary during combined antiretroviral therapy. AIDS Res. Hum. Retroviruses 34, 123-125. doi: 10.1089/AID.2017.0254

Norton, N. J., Mok, H. P., Sharif, F., Hirst, J. C., and Lever, A. M. L. (2019). HIV silencing and inducibility are heterogeneous and are affected by factors intrinsic to the virus. mBio 10:e0188-19. doi: 10.1128/mBio.00188-19

Novis, C. L., Archin, N. M., Buzon, M. J., Verdin, E., Round, J. L., and Lichterfeld, M. (2013). Reactivation of latent HIV-1 in central memory CD4+ T cells through TLR-1/2 stimulation. Retrovirology 10:119. doi: 10.1186/1742-469010- 119 
Offersen, R., Nissen, S. K., Rasmussen, T. A., Østergaard, L., Denton, P. W., Søgaard, O. S., et al. (2016). A novel toll-like receptor 9 agonist, MGN1703, enhances HIV-1 transcription and NK cell-mediated inhibition of HIV-1infected autologous CD4+ T cells. J. Virol. 90, 4441-4453. doi: 10.1128/JVI. 00222-16

Oliveira, M. F., Chaillon, A., Nakazawa, M., Vargas, M., Letendre, S. L., and Strain, M. C. (2017). Early antiretroviral therapy is associated with lower HIV DNA molecular diversity and lower inflammation in cerebrospinal fluid but does not prevent the establishment of compartmentalized HIV DNA populations. PLoS Pathog. 13:e1006112. doi: 10.1371/journal.ppat.1006112

Osuna, C. E., Lim, S.-Y., Kublin, J. L., Apps, R., Chen, E., Mota, T. M., et al. (2018). Evidence that CD32a does not mark the HIV-1 latent reservoir. Nature 561, E20-E28.

Pace, M. J., Graf, E. H., Agosto, L. M., Mexas, A. M., Male, F., Brady, T., et al. (2012). Directly infected resting CD4+T cells can produce HIV Gag without spreading infection in a model of HIV latency. PLoS Pathog. 8:e1002818. doi: 10.1371/journal.ppat.1002818

Pache, L., Dutra, M. S., Spivak, A. M., Marlett, J. M., Murry, J. P., Hwang, Y., et al. (2015). BIRC2/cIAP1 is a negative regulator of HIV-1 transcription and can be targeted by Smac mimetics to promote reversal of viral latency. Cell Host Microbe 18, 345-353. doi: 10.1016/j.chom.2015.08.009

Palacios, J. A., Pérez-Piñar, T., Toro, C., Sanz-Minguela, B., Moreno, V., Valencia, E., et al. (2012). Long-term nonprogressor and elite controller patients who control viremia have a higher percentage of methylation in their HIV-1 proviral promoters than aviremic patients receiving highly active antiretroviral therapy. J. Virol. 86, 13081-13084. doi: 10.1128/JVI.01741-12

Pallikkuth, S., Sharkey, M., Babic, D. Z., Gupta, S., Stone, G. W., Fischl, M. A., et al. (2015). Peripheral T follicular helper cells are the major HIV reservoir within central memory CD4 T cells in peripheral blood from chronically HIV-infected individuals on combination antiretroviral therapy. J. Virol. 90, 2718-2728. doi: 10.1128/JVI.02883-15

Paranjpe, S., Craigo, J., Patterson, B., Ding, M., Barroso, P., Harrison, L., et al. (2002). Subcompartmentalization of HIV-1 quasispecies between seminal cells and seminal plasma indicates their origin in distinct genital tissues. AIDS Res. Hum. Retroviruses 18, 1271-1280. doi: 10.1089/08892220232088 6316

Pardons, M., Baxter, A. E., Massanella, M., Pagliuzza, A., Fromentin, R., and Dufour, C. (2019). Single-cell characterization and quantification of translationcompetent viral reservoirs in treated and untreated HIV infection. PLoS Pathog. 15:e1007619. doi: 10.1371/journal.ppat.1007619

Passaes, C. P. B., Bruel, T., Decalf, J., David, A., Angin, M., and Monceaux, V. (2017). Ultrasensitive HIV-1 p24 assay detects single infected cells and differences in reservoir induction by latency reversal agents. J. Virol. 91:e0229616. doi: 10.1128/JVI.02296-16

Penton, P. K., and Blackard, J. T. (2014). Analysis of HIV quasispecies suggests compartmentalization in the liver. AIDS Res. Hum. Retroviruses 30, 394-402. doi: 10.1089/AID.2013.0146

Perreau, M., Savoye, A.-L., De Crignis, E., Corpataux, J.-M., Cubas, R., and Haddad, E. K. (2013). Follicular helper T cells serve as the major CD4 T cell compartment for HIV-1 infection, replication, and production. J. Exp. Med. 210, 143-156. doi: 10.1084/jem.20121932

Piantadosi, A., Freije, C. A., Gosmann, C., Ye, S., Park, D., Schaffner, S. F., et al. (2019). Metagenomic sequencing of HIV-1 in the blood and female genital tract reveals little quasispecies diversity during acute infection. J. Virol. 93:e00804-18. doi: 10.1128/JVI.00804-18

Pillai, S. K., Good, B., Pond, S. K., Wong, J. K., Strain, M. C., Richman, D. D., et al. (2005). Semen-specific genetic characteristics of human immunodeficiency virus type 1 env. J. Virol. 79, 1734-1742. doi: 10.1128/jvi.79.3.1734-1742.2005

Pomerantz, R. J., Trono, D., Feinberg, M. B., and Baltimore, D. (1990). Cells nonproductively infected with HIV-1 exhibit an aberrant pattern of viral RNA expression: a molecular model for latency. Cell 61, 1271-1276. doi: 10.1016/ 0092-8674(90)90691-7

Pulliam, L., Gascon, R., Stubblebine, M., McGuire, D., and McGrath, M. S. (1997). Unique monocyte subset in patients with AIDS dementia. Lancet 349, 692-695. doi: 10.1016/s0140-6736(96)10178-1

Quivy, V., Adam, E., Collette, Y., Demonte, D., Chariot, A., Vanhulle, C., et al. (2002). Synergistic activation of human immunodeficiency virus type 1 promoter activity by NF-kappaB and inhibitors of deacetylases: potential perspectives for the development of therapeutic strategies. J. Virol. 76, 1109111103. doi: 10.1128/jvi.76.21.11091-11103.2002

Ramakrishnan, R., Dow, E. C., and Rice, A. P. (2009). Characterization of Cdk9 T-loop phosphorylation in resting and activated CD4(+) T lymphocytes. J. Leukoc. Biol. 86, 1345-1350. doi: 10.1189/jlb.0509309

Ramakrishnan, R., Liu, H., and Rice, A. P. (2015). Short communication: SAHA (vorinostat) induces CDK9 Thr-186 (T-loop) phosphorylation in resting CD4+ T cells: implications for reactivation of latent HIV. AIDS Res. Hum. Retroviruses 31, 137-141. doi: 10.1089/AID.2013.0288

Rao, S., Amorim, R., Niu, M., Temzi, A., and Mouland, A. J. (2018). The RNA surveillance proteins UPF1, UPF2 and SMG6 affect HIV-1 reactivation at a post-transcriptional level. Retrovirology 15:42. doi: 10.1186/s12977-018-0 $425-2$

Rasmussen, T. A., Schmeltz Søgaard, O., Brinkmann, C., Wightman, F., Lewin, S. R., and Melchjorsen, J. (2013). Comparison of HDAC inhibitors in clinical development: effect on HIV production in latently infected cells and T-cell activation. Hum. Vaccin. Immunother. 9, 993-1001. doi: 10.4161/hv.23800

Rasmussen, T. A., Tolstrup, M., Brinkmann, C. R., Olesen, R., Erikstrup, C., and Solomon, A. (2014). Panobinostat, a histone deacetylase inhibitor, for latent-virus reactivation in HIV-infected patients on suppressive antiretroviral therapy: a phase $1 / 2$, single group, clinical trial. Lancet $H I V$ 1, e13-e21. doi: 10.1016/S2352-3018(14)70014-1

Rasmussen, T. A., Tolstrup, M., Møller, H. J., Brinkmann, C. R., Olesen, R., and Erikstrup, C. (2015). Activation of latent human immunodeficiency virus by the histone deacetylase inhibitor panobinostat: a pilot study to assess effects on the central nervous system. Open Forum Infect. Dis. 2:ofv037. doi: 10.1093/ofid/ ofv037

Reuse, S., Calao, M., Kabeya, K., Guiguen, A., Gatot, J.-S., Quivy, V., et al. (2009). Synergistic activation of HIV-1 expression by deacetylase inhibitors and prostratin: implications for treatment of latent infection. PLoS One 4:e6093. doi: 10.1371/journal.pone.0006093

Riou, C., Yassine-Diab, B., Van grevenynghe, J., Somogyi, R., Greller, L. D., and Gagnon, D. (2007). Convergence of TCR and cytokine signaling leads to FOXO3a phosphorylation and drives the survival of CD4+ central memory $\mathrm{T}$ cells. J. Exp. Med. 204, 79-91. doi: 10.1084/jem.20061681

Rochat, M. A., Schlaepfer, E., and Speck, R. F. (2017). Promising role of toll-like receptor 8 agonist in concert with prostratin for activation of silent HIV. J. Virol. 91:e02084-16. doi: 10.1128/JVI.02084-16

Rohr, O., Lecestre, D., Chasserot-Golaz, S., Marban, C., Avram, D., Aunis, D., et al. (2003). Recruitment of tat to heterochromatin protein HP1 via interaction with CTIP2 inhibits human immunodeficiency virus type 1 replication in microglial cells. J. Virol. 77, 5415-5427. doi: 10.1128/jvi.77.9.5415-5427.2003

Rothenberger, M. K., Keele, B. F., Wietgrefe, S. W., Fletcher, C. V., Beilman, G. J., and Chipman, J. G. (2015). Large number of rebounding/founder HIV variants emerge from multifocal infection in lymphatic tissues after treatment interruption. Proc. Natl. Acad. Sci. U.S.A. 112, E1126-E1134. doi: 10.1073/pnas. 1414926112

Rozera, G., Abbate, I., Vlassi, C., Giombini, E., Lionetti, R., Selleri, M., et al. (2014). Quasispecies tropism and compartmentalization in gut and peripheral blood during early and chronic phases of HIV-1 infection: possible correlation with immune activation markers. Clin. Microbiol. Infect. 20, 157-166. doi: 10.1111/ 1469-0691.12367

Saayman, S., Ackley, A., Turner, A.-M. W., Famiglietti, M., Bosque, A., Clemson, M., et al. (2014). An HIV-encoded antisense long noncoding RNA epigenetically regulates viral transcription. Mol. Ther. 22, 1164-1175. doi: 10 . 1038/mt.2014.29

Sadowski, I., and Hashemi, F. B. (2019). Strategies to eradicate HIV from infected patients: elimination of latent provirus reservoirs. Cell. Mol. Life Sci. 76, 35833600. doi: 10.1007/s00018-019-03156-8

Salantes, D. B., Zheng, Y., Mampe, F., Srivastava, T., Beg, S., Lai, J., et al. (2018). HIV-1 latent reservoir size and diversity are stable following brief treatment interruption. J. Clin. Invest. 128, 3102-3115. doi: 10.1172/JCI120194

Sarracino, A., Gharu, L., Kula, A., Pasternak, A. O., Avettand-Fenoel, V., Rouzioux, C., et al. (2018). Posttranscriptional regulation of HIV-1 gene expression during replication and reactivation from latency by nuclear matrix protein MATR3. mBio 9:e02158-18. doi: 10.1128/mBio.02158-18

Schlaepfer, E., and Speck, R. F. (2011). TLR8 activates HIV from latently infected cells of myeloid-monocytic origin directly via the MAPK pathway and from 
latently infected CD4+ T cells indirectly via TNF- $\alpha$. J. Immunol. 186, 43144324. doi: 10.4049/jimmunol.1003174

Schnell, G., Price, R. W., Swanstrom, R., and Spudich, S. (2010). Compartmentalization and clonal amplification of HIV-1 variants in the cerebrospinal fluid during primary infection. J. Virol. 84, 2395-2407. doi: 10.1128/JVI.01863-09

Schröder, A. R. W., Shinn, P., Chen, H., Berry, C., Ecker, J. R., and Bushman, F. (2002). HIV-1 integration in the human genome favors active genes and local hotspots. Cell 110, 521-529. doi: 10.1016/s0092-8674(02)00864-4

Schwartz, C., Wallet, C., De Rovere, M., Van Assche, J., Daoud, F., and Rohr, O. (2019). Microglial cells: the main HIV-1 reservoir in the brain. Front. Cell. Infect. Microbiol. 9:362. doi: 10.3389/fcimb.2019.00362

Scully, E. P., Gandhi, M., Johnston, R., Hoh, R., Lockhart, A., and Dobrowolski, C. (2019). Sex-based differences in human immunodeficiency virus type 1 reservoir activity and residual immune activation. J. Infect. Dis. 219, 1084-1094. doi: 10.1093/infdis/jiy617

Scully, E. P., Rutishauser, R. L., Simoneau, C. R., Delagrèverie, H., Euler, Z., Thanh, C., et al. (2018). Inconsistent HIV reservoir dynamics and immune responses following anti-PD-1 therapy in cancer patients with HIV infection. Ann. Oncol. 29, 2141-2142. doi: 10.1093/annonc/mdy259

Sebastian, N. T., Zaikos, T. D., Terry, V., Taschuk, F., McNamara, L. A., OnafuwaNuga, A., et al. (2017). CD4 is expressed on a heterogeneous subset of hematopoietic progenitors, which persistently harbor CXCR4 and CCR5-tropic HIV proviral genomes in vivo. PLoS Pathog. 13:e1006509. doi: 10.1371/journal. ppat.1006509

Sengupta, S., and Siliciano, R. F. (2018). Targeting the latent reservoir for HIV-1. Immunity 48, 872-895. doi: 10.1016/j.immuni.2018.04.030

Serra-Peinado, C., Grau-Expósito, J., Luque-Ballesteros, L., Astorga-Gamaza, A., Navarro, J., Gallego-Rodriguez, J., et al. (2019). Expression of CD20 after viral reactivation renders HIV-reservoir cells susceptible to rituximab. Nat. Commun. 10:3705. doi: 10.1038/s41467-019-11556-4

Sewald, X., Ladinsky, M. S., Uchil, P. D., Beloor, J., Pi, R., Herrmann, C., et al. (2015). Retroviruses use CD169-mediated trans-infection of permissive lymphocytes to establish infection. Science 350, 563-567. doi: 10.1126/science. aab2749

Shan, L., Deng, K., Shroff, N. S., Durand, C. M., Rabi, S. A., and Yang, H.-C. (2012). Stimulation of HIV-1-specific cytolytic T lymphocytes facilitates elimination of latent viral reservoir after virus reactivation. Immunity 36, 491-501. doi: 10.1016/j.immuni.2012.01.014

Shen, R., Kappes, J. C., Smythies, L. E., Richter, H. E., Novak, L., and Smith, P. D. (2014). Vaginal myeloid dendritic cells transmit founder HIV-1. J. Virol. 88, 7683-7688. doi: 10.1128/JVI.00766-14

Sheth, P. M., Kovacs, C., Kemal, K. S., Jones, R. B., Raboud, J. M., and Pilon, R. (2009). Persistent HIV RNA shedding in semen despite effective antiretroviral therapy. AIDS 23, 2050-2054. doi: 10.1097/QAD.0b013e328330 3e 04

Siddiqui, S., Perez, S., Gao, Y., Doyle-Meyers, L., Foley, B. T., Li, Q., et al. (2019). Persistent viral reservoirs in lymphoid tissues in SIV-infected rhesus macaques of Chinese-origin on suppressive antiretroviral therapy. Viruses 11:E105. doi: 10.3390/v11020105

Singh, P. K., Plumb, M. R., Ferris, A. L., Iben, J. R., and Wu, X. (2015). LEDGF/p75 interacts with mRNA splicing factors and targets HIV-1 integration to highly spliced genes. Genes Dev. 29, 2287-2297. doi: 10.1101/gad.267609.115

Sivro, A., Schuetz, A., Sheward, D., Joag, V., Yegorov, S., and Liebenberg, L. J. (2018). Integrin $\alpha 4 \beta 7$ expression on peripheral blood CD4+ T cells predicts HIV acquisition and disease progression outcomes. Sci. Transl. Med. 10:eaam6354. doi: 10.1126/scitranslmed.aam6354

Smith, B. A., Gartner, S., Liu, Y., Perelson, A. S., Stilianakis, N. I., Keele, B. F., et al. (2001). Persistence of infectious HIV on follicular dendritic cells. J. Immunol. 166, 690-696. doi: 10.4049/jimmunol.166.1.690

Søgaard, O. S., Graversen, M. E., Leth, S., Olesen, R., Brinkmann, C. R., and Nissen, S. K. (2015). The depsipeptide romidepsin reverses HIV-1 latency in vivo. PLoS Pathog. 11:e1005142. doi: 10.1371/journal.ppat.1005142

Sonza, S., Mutimer, H. P., Oelrichs, R., Jardine, D., Harvey, K., and Dunne, A. (2001). Monocytes harbour replication-competent, non-latent HIV-1 in patients on highly active antiretroviral therapy. AIDS 15, 17-22. doi: 10.1097/ 00002030-200101050-00005
Soriano-Sarabia, N., Archin, N. M., Bateson, R., Dahl, N. P., Crooks, A. M., Kuruc, J. D., et al. (2015). Peripheral V $\gamma 9 \mathrm{~V} \delta 2 \mathrm{~T}$ cells are a novel reservoir of latent HIV infection. PLoS Pathog. 11:e1005201. doi: 10.1371/journal.ppat.1005201

Spina, C. A., Anderson, J., Archin, N. M., Bosque, A., Chan, J., and Famiglietti, M. (2013). An in-depth comparison of latent HIV-1 reactivation in multiple cell model systems and resting CD4+ T cells from aviremic patients. PLoS Pathog. 9:e1003834. doi: 10.1371/journal.ppat.1003834

Spivak, A. M., Andrade, A., Eisele, E., Hoh, R., Bacchetti, P., and Bumpus, N. N. (2014). A pilot study assessing the safety and latency-reversing activity of disulfiram in HIV-1-infected adults on antiretroviral therapy. Clin. Infect. Dis. 58, 883-890. doi: 10.1093/cid/cit813

Spivak, A. M., Bosque, A., Balch, A. H., Smyth, D., Martins, L., and Planelles, V. (2015). Ex vivo bioactivity and HIV-1 latency reversal by ingenol dibenzoate and panobinostat in resting CD4(+) T cells from aviremic patients. Antimicrob. Agents Chemother. 59, 5984-5991. doi: 10.1128/AAC.01077-15

Spivak, A. M., and Planelles, V. (2018). Novel latency reversal agents for HIV-1 cure. Annu. Rev. Med. 69, 421-436. doi: 10.1146/annurev-med-052716-031710

Sturdevant, C. B., Joseph, S. B., Schnell, G., Price, R. W., Swanstrom, R., and Spudich, S. (2015). Compartmentalized replication of R5 T cell-tropic HIV1 in the central nervous system early in the course of infection. PLoS Pathog. 11:e1004720. doi: 10.1371/journal.ppat.1004720

Sung, T.-L., and Rice, A. P. (2009). miR-198 inhibits HIV-1 gene expression and replication in monocytes and its mechanism of action appears to involve repression of cyclin T1. PLoS Pathog. 5:e1000263. doi: 10.1371/journal.ppat. 1000263

Suzuki, K., Hattori, S., Marks, K., Ahlenstiel, C., Maeda, Y., and Ishida, T. (2013). Promoter targeting shRNA suppresses HIV-1 infection in vivo through transcriptional gene silencing. Mol. Ther. Nucleic Acids 2:e137. doi: 10.1038/ mtna.2013.64

Tapia, G., Højen, J. F., Ökvist, M., Olesen, R., Leth, S., and Nissen, S. K. (2017). Sequential Vacc- $4 \mathrm{x}$ and romidepsin during combination antiretroviral therapy (cART): immune responses to Vacc- $4 \mathrm{x}$ regions on $\mathrm{p} 24$ and changes in HIV reservoirs. J. Infect. 75, 555-571. doi: 10.1016/j.jinf.2017.09.004

Taura, M., Song, E., Ho, Y.-C., and Iwasaki, A. (2019). Apobec3A maintains HIV1 latency through recruitment of epigenetic silencing machinery to the long terminal repeat. Proc. Natl. Acad. Sci. U.S.A. 116, 2282-2289. doi: 10.1073/pnas. 1819386116

Tchasovnikarova, I. A., Timms, R. T., Douse, C. H., Roberts, R. C., Dougan, G., Kingston, R. E., et al. (2017). Hyperactivation of HUSH complex function by charcot-marie-tooth disease mutation in MORC2. Nat. Genet. 49, 1035-1044. doi: $10.1038 /$ ng.3878

Tchasovnikarova, I. A., Timms, R. T., Matheson, N. J., Wals, K., Antrobus, R., and Göttgens, B. (2015). Epigenetic silencing by the HUSH complex mediates position-effect variegation in human cells. Science 348, 1481-1485. doi: 10.1126/ science.aaa7227

Telwatte, S., Lee, S., Somsouk, M., Hatano, H., Baker, C., Kaiser, P., et al. (2018). Gut and blood differ in constitutive blocks to HIV transcription, suggesting tissuespecific differences in the mechanisms that govern HIV latency. PLoS Pathog. 14:e1007357. doi: 10.1371/journal.ppat.1007357

Thorlund, K., Horwitz, M. S., Fife, B. T., Lester, R., and Cameron, D. W. (2017). Landscape review of current HIV 'kick and kill' cure research - some kicking, not enough killing. BMC Infect. Dis. 17:595. doi: 10.1186/s12879-017-2683-3

Thornhill, J. P., Pace, M., Martin, G. E., Hoare, J., Peake, S., Herrera, C., et al. (2019). CD32 expressing doublets in HIV-infected gut-associated lymphoid tissue are associated with a $\mathrm{T}$ follicular helper cell phenotype. Mucosal Immunol. 12, 1212-1219. doi: 10.1038/s41385-019-0180-2

Tran, T.-A., de Goër de Herve, M.-G., Hendel-Chavez, H., Dembele, B., Le Névot, E., and Abbed, K. (2008). Resting regulatory CD4 T cells: a site of HIV persistence in patients on long-term effective antiretroviral therapy. PLoS One 3:e3305. doi: 10.1371/journal.pone.0003305

Trejbalová, K., Kováøová, D., Blažková, J., Machala, L., Jilich, D., and Weber, J. (2016). Development of 5' LTR DNA methylation of latent HIV-1 provirus in cell line models and in long-term-infected individuals. Clin. Epigenetics 8:19. doi: 10.1186/s13148-016-0185-6

Triboulet, R., Mari, B., Lin, Y.-L., Chable-Bessia, C., Bennasser, Y., Lebrigand, K., et al. (2007). Suppression of microRNA-silencing pathway by HIV-1 during virus replication. Science 315, 1579-1582. doi: 10.1126/science.1136319 
Tripathy, M. K., McManamy, M. E. M., Burch, B. D., Archin, N. M., and Margolis, D. M. (2015). H3K27 demethylation at the proviral promoter sensitizes latent HIV to the effects of vorinostat in ex vivo cultures of resting CD4+ T cells. J. Virol. 89, 8392-8405. doi: 10.1128/JVI.00572-15

Tsai, A., Irrinki, A., Kaur, J., Cihlar, T., Kukolj, G., Sloan, D. D., et al. (2017). Toll-like receptor 7 agonist GS-9620 induces HIV expression and HIV-specific immunity in cells from HIV-infected individuals on suppressive antiretroviral therapy. J. Virol. 91:e02166-16. doi: 10.1128/JVI.02166-16

Turrini, F., Marelli, S., Kajaste-Rudnitski, A., Lusic, M., Van Lint, C., Das, A. T., et al. (2015). HIV-1 transcriptional silencing caused by TRIM22 inhibition of Sp1 binding to the viral promoter. Retrovirology 12:104. doi: 10.1186/s12977015-0230-0

Turrini, F., Saliu, F., Forlani, G., Das, A. T., Van Lint, C., Accolla, R. S., et al. (2019). Interferon-inducible TRIM22 contributes to maintenance of HIV-1 proviral latency in T cell lines. Virus Res. 269:197631. doi: 10.1016/j.virusres.2019.05.009

Tyagi, M., and Karn, J. (2007). CBF-1 promotes transcriptional silencing during the establishment of HIV-1 latency. EMBO J. 26, 4985-4995. doi: 10.1038/sj.emboj. 7601928

Valcour, V. G., Ananworanich, J., Agsalda, M., Sailasuta, N., Chalermchai, T., Schuetz, A., et al. (2013). HIV DNA reservoir increases risk for cognitive disorders in cART-naïve patients. PLoS One 8:e70164. doi: 10.1371/journal. pone.0070164

Valcour, V. G., Shiramizu, B. T., and Shikuma, C. M. (2010). HIV DNA in circulating monocytes as a mechanism to dementia and other HIV complications. J. Leukoc. Biol. 87, 621-626. doi: 10.1189/jlb.0809571

Valcour, V. G., Shiramizu, B. T., Sithinamsuwan, P., Nidhinandana, S., Ratto-Kim, S., and Ananworanich, J. (2009). Asia research collaboration with the University of Hawaii 001 protocol team. HIV DNA and cognition in a thai longitudinal HAART initiation cohort: the SEARCH 001 cohort study. Neurology 72, 992998. doi: 10.1212/01.wnl.0000344404.12759.83

van der Hoek, L., Sol, C. J., Maas, J., Lukashov, V. V., Kuiken, C. L., and Goudsmit, J. (1998). Genetic differences between human immunodeficiency virus type 1 subpopulations in faeces and serum. J. Gen. Virol. 79(Pt 2), 259-267. doi: 10.1099/0022-1317-79-2-259

Van Lint, C., Bouchat, S., and Marcello, A. (2013). HIV-1 transcription and latency: an update. Retrovirology 10:67. doi: 10.1186/1742-4690-10-67

Van Lint, C., Emiliani, S., Ott, M., and Verdin, E. (1996). Transcriptional activation and chromatin remodeling of the HIV-1 promoter in response to histone acetylation. EMBO J. 15, 1112-1120. doi: 10.1002/j.1460-2075.1996.tb00 449.x

Venanzi Rullo, E., Cannon, L., Pinzone, M. R., Ceccarelli, M., Nunnari, G., and O'Doherty, U. (2019). Genetic evidence that Naïve T cells can contribute significantly to the HIV intact reservoir: time to re-evaluate their role. Clin. Infect. Dis. 69, 2236-2237. doi: 10.1093/cid/ciz378

Verdin, E., Paras, P., and Van Lint, C. (1993). Chromatin disruption in the promoter of human immunodeficiency virus type 1 during transcriptional activation. EMBO J. 12, 3249-3259. doi: 10.1002/j.1460-2075.1993.tb05994.x

Vibholm, L. K., Lorenzi, J. C. C., Pai, J. A., Cohen, Y. Z., Oliveira, T. Y., and Barton, J. P. (2019). Characterization of intact proviruses in blood and lymph node from HIV-infected individuals undergoing analytical treatment interruption. J. Virol. 93:e01920-18. doi: 10.1128/JVI.01920-18

von Stockenstrom, S., Odevall, L., Lee, E., Sinclair, E., Bacchetti, P., Killian, M., et al. (2015). Longitudinal genetic characterization reveals that cell proliferation maintains a persistent HIV type 1 DNA pool during effective HIV therapy. J. Infect. Dis. 212, 596-607. doi: 10.1093/infdis/jiv092

Vranckx, L. S., Demeulemeester, J., Saleh, S., Boll, A., Vansant, G., and Schrijvers, R. (2016). LEDGIN-mediated inhibition of integrase-LEDGF/p75 interaction reduces reactivation of residual latent HIV. EBioMedicine 8, 248-264. doi: 10. 1016/j.ebiom.2016.04.039

Walker-Sperling, V. E., Pohlmeyer, C. W., Tarwater, P. M., and Blankson, J. N. (2016). The effect of latency reversal agents on primary CD8+ T cells: implications for shock and kill strategies for human immunodeficiency virus eradication. EBioMedicine 8, 217-229. doi: 10.1016/j.ebiom.2016.04.019

Wan, Z., and Chen, X. (2014). Triptolide inhibits human immunodeficiency virus type 1 replication by promoting proteasomal degradation of Tat protein. Retrovirology 11:88. doi: 10.1186/s12977-014-0088-6

Weber, S., Weiser, B., Kemal, K. S., Burger, H., Ramirez, C. M., and Korn, K. (2014). Epigenetic analysis of HIV-1 proviral genomes from infected individuals: predominance of unmethylated CpG's. Virology 449, 181-189. doi: 10.1016/j. virol.2013.11.013

Wei, P., Garber, M. E., Fang, S. M., Fischer, W. H., and Jones, K. A. (1998). A novel CDK9-associated C-type cyclin interacts directly with HIV-1 Tat and mediates its high-affinity, loop-specific binding to TAR RNA. Cell 92, 451-462. doi: 10.1016/s0092-8674(00)80939-3

Weinberger, L. S., Burnett, J. C., Toettcher, J. E., Arkin, A. P., and Schaffer, D. V. (2005). Stochastic gene expression in a lentiviral positive-feedback loop: HIV-1 Tat fluctuations drive phenotypic diversity. Cell 122, 169-182. doi: 10.1016/j. cell.2005.06.006

Weng, K.-F., Hung, C.-T., Hsieh, P.-T., Li, M.-L., Chen, G.-W., Kung, Y. A., et al. (2014). A cytoplasmic RNA virus generates functional viral small RNAs and regulates viral IRES activity in mammalian cells. Nucleic Acids Res. 42, 12789-12805. doi: 10.1093/nar/gku952

Wightman, F., Lu, H. K., Solomon, A. E., Saleh, S., Harman, A. N., and Cunningham, A. L. (2013). Entinostat is a histone deacetylase inhibitor selective for class 1 histone deacetylases and activates HIV production from latently infected primary T cells. AIDS 27, 2853-2862. doi: 10.1097/QAD. 0000000000000067

Wightman, F., Solomon, A., Khoury, G., Green, J. A., Gray, L., and Gorry, P. R. (2010). Both CD31(+) and CD31- naive CD4(+) T cells are persistent HIV type 1-infected reservoirs in individuals receiving antiretroviral therapy. J. Infect. Dis. 202, 1738-1748. doi: 10.1086/656721

Wightman, F., Solomon, A., Kumar, S. S., Urriola, N., Gallagher, K., Hiener, B., et al. (2015). Effect of ipilimumab on the HIV reservoir in an HIV-infected individual with metastatic melanoma. AIDS 29, 504-506. doi: 10.1097/qad. 0000000000000562

Williams, D. W., Veenstra, M., Gaskill, P. J., Morgello, S., Calderon, T. M., and Berman, J. W. (2014). Monocytes mediate HIV neuropathogenesis: mechanisms that contribute to HIV associated neurocognitive disorders. Curr. HIV Res. 12, 85-96. doi: 10.2174/1570162x12666140526114526

Williams, S. A., Chen, L.-F., Kwon, H., Ruiz-Jarabo, C. M., Verdin, E., and Greene, W. C. (2006). NF-kappaB p50 promotes HIV latency through HDAC recruitment and repression of transcriptional initiation. EMBO J. 25, 139-149. doi: 10.1038/sj.emboj.7600900

Winckelmann, A., Barton, K., Hiener, B., Schlub, T. E., Shao, W., and Rasmussen, T. A. (2017). Romidepsin-induced HIV-1 viremia during effective antiretroviral therapy contains identical viral sequences with few deleterious mutations. AIDS 31, 771-779. doi: 10.1097/QAD.0000000000001400

Winckelmann, A., Morcilla, V., Shao, W., Schleimann, M. H., Hojen, J. F., Schlub, T. E., et al. (2018). Genetic characterization of the HIV-1 reservoir after Vacc$4 \mathrm{x}$ and romidepsin therapy in HIV-1-infected individuals. AIDS 32, 1793-1802. doi: 10.1097/QAD.0000000000001861

Winston, J. A., Bruggeman, L. A., Ross, M. D., Jacobson, J., Ross, L., D’Agati, V. D., et al. (2001). Nephropathy and establishment of a renal reservoir of HIV type 1 during primary infection. N. Engl. J. Med. 344, 1979-1984. doi: 10.1056/nejm200106283442604

Xing, S., Bullen, C. K., Shroff, N. S., Shan, L., Yang, H.-C., and Manucci, J. L. (2011). Disulfiram reactivates latent HIV-1 in a Bcl-2-transduced primary CD4+ T cell model without inducing global T cell activation. J. Virol. 85, 6060-6064. doi: $10.1128 /$ JVI.02033-10

Yamaguchi, Y., Takagi, T., Wada, T., Yano, K., Furuya, A., Sugimoto, S., et al. (1999). NELF, a multisubunit complex containing RD, cooperates with DSIF to repress RNA polymerase II elongation. Cell 97, 41-51. doi: 10.1016/s0092-8674(00) 80713-8

Yang, W., Sun, Z., Hua, C., Wang, Q., Xu, W., Deng, Q., et al. (2018). Chidamide, a histone deacetylase inhibitor-based anticancer drug, effectively reactivates latent HIV-1 provirus. Microbes Infect. 20, 626-634. doi: 10.1016/j.micinf.2017. 10.003

Yang, Z., Zhu, Q., Luo, K., and Zhou, Q. (2001). The 7SK small nuclear RNA inhibits the CDK9/cyclin T1 kinase to control transcription. Nature 414, 317322. doi: $10.1038 / 35104575$

Ylisastigui, L., Archin, N. M., Lehrman, G., Bosch, R. J., and Margolis, D. M. (2004). Coaxing HIV-1 from resting CD4 T cells: histone deacetylase inhibition allows latent viral expression. AIDS 18, 1101-1108. doi: 10.1097/00002030200405210-00003

Yucha, R. W., Hobbs, K. S., Hanhauser, E., Hogan, L. E., Nieves, W., and Ozen, M. O. (2017). High-throughput characterization of HIV-1 reservoir reactivation 
using a single-cell-in-droplet PCR assay. EBioMedicine 20, 217-229. doi: 10. 1016/j.ebiom.2017.05.006

Yukl, S. A., Kaiser, P., Kim, P., Telwatte, S., Joshi, S. K., Vu, M., et al. (2018). HIV latency in isolated patient $\mathrm{CD} 4+\mathrm{T}$ cells may be due to blocks in HIV transcriptional elongation, completion, and splicing. Sci. Transl. Med. 10:eaa9927. doi: 10.1126/scitranslmed.aap9927

Yukl, S. A., Shergill, A. K., Ho, T., Killian, M., Girling, V., Epling, L., et al. (2013). The distribution of HIV DNA and RNA in cell subsets differs in gut and blood of HIV-positive patients on ART: implications for viral persistence. J. Infect. Dis. 208, 1212-1220. doi: 10.1093/infdis/jit308

Zaikos, T. D., Terry, V. H., Sebastian Kettinger, N. T., Lubow, J., Painter, M. M., and Virgilio, M. C. (2018). Hematopoietic stem and progenitor cells are a distinct HIV reservoir that contributes to persistent viremia in suppressed patients. Cell Rep. 25, 3759-3773.e9. doi: 10.1016/j.celrep.2018.1 1.104

Zapata, J. C., Campilongo, F., Barclay, R. A., DeMarino, C., Iglesias-Ussel, M. D., Kashanchi, F., et al. (2017). The human immunodeficiency virus 1 ASP RNA promotes viral latency by recruiting the polycomb repressor complex 2 and promoting nucleosome assembly. Virology 506, 34-44. doi: 10.1016/j.virol.2017. 03.002
Zerbato, J. M., McMahon, D. K., Sobolewski, M. D., Mellors, J. W., and SluisCremer, N. (2019). Naïve CD4+ T cells harbor a large inducible reservoir of latent, replication-competent HIV-1. Clin. Infect. Dis. 69, 1919-1925. doi: $10.1093 / \mathrm{cid} / \mathrm{ciz} 108$

Zhang, Z., Nikolai, B. C., Gates, L. A., Jung, S. Y., Siwak, E. B., and He, B. (2017). Crosstalk between histone modifications indicates that inhibition of arginine methyltransferase CARM1 activity reverses HIV latency. Nucleic Acids Res. 45, 9348-9360. doi: 10.1093/nar/gkx550

Conflict of Interest: The authors declare that the research was conducted in the absence of any commercial or financial relationships that could be construed as a potential conflict of interest.

Copyright (c) 2020 Ait-Ammar, Kula, Darcis, Verdikt, De Wit, Gautier, Mallon, Marcello, Rohr and Van Lint. This is an open-access article distributed under the terms of the Creative Commons Attribution License (CC BY). The use, distribution or reproduction in other forums is permitted, provided the original author(s) and the copyright owner(s) are credited and that the original publication in this journal is cited, in accordance with accepted academic practice. No use, distribution or reproduction is permitted which does not comply with these terms. 